\title{
A POSITIVE MODEL OF GROWTH AND POLLUTION CONTROLS
}

Larry E. Jones

Rodolfo E. Manuelli

Working Paper No. 5205

\section{NATIONAL BUREAU OF ECONOMIC RESEARCH 1050 Massachusetts Avenue Cambridge, MA 02138 \\ August 1995}

We thank Graziella Bertocchi, Hal Cole, Mike Dotsey, Jeremy Greenwood, Arik Levinson, Sergio Rebelo, Karl Shell and seminar participants at the University of Chicago, Cornell University, Rochester University, University of Minnesota, University of Michigan, University of Wisconsin and the Federal Reserve Bank of Richmond for their comments and the National Science Foundation for financial support. This paper is part of NBER's research program in Growth. Any opinions expressed are those of the authors and not those of the National Bureau of Economic Research.

(C) 1995 by Larry E. Jones and Rodolfo E. Manuelli. All rights reserved. Short sections of text, not to exceed two paragraphs, may be quoted without explicit permission provided that full credit, including () notice, is given to the source. 


\title{
A POSITIVE MODEL OF GROWTH AND POLLUTION CONTROLS
}

\begin{abstract}
The most recent addition to the economics of gloom concerns the interplay between income and environmental degradation. The main question raised is whether or not continued environmental degradation is a necessary part of the process of industrialization. Will pollution continue to increase without bound as more and more countries pass through the development phase or will it be controlled? Intuitively, if 'clean air' is a normal good, we would expect that societies might be 'self-regulating' in the sense that as income increases, pollution controls also increase. However, this intuition is somewhat misleading as the presence of external effects is an essential feature of environmental regulation.

This paper describes a growth model in which pollutants are internal to a jurisdiction. To this end we develop a model of the joint determination of the rate of development of the economy through market interactions and the extent of pollution regulation through collective decision making. We show that depending on the collective decision making mechanism in place, the time path of pollution can display an inverted U shape, a "sideways mirrored" $S$, or an increasing (but bounded) level over time.

This paper contributes to the literature on both the large differences in income per capita across countries as well as the discrepancies in their growth rates. It shows that by relying on collective decision making mechanisms to choose policies, the dynamics of convex models can resemble those usually ascribed to models of multiple equilibria.

Larry E. Jones

MEDS-Kellogg School

Northwestern University

Evanston, IL 60208

and NBER

Rodolfo E. Manuelli

Department of Economics

University of Wisconsin

Madison, WI 53705

and NBER
\end{abstract}




\section{Introduction}

The most recent addition to the economics of gloom (see World Bank (1993)) concerns the interplay between income and environmental degradation. The main question raised is whether or not continued environmental degradation is a necessary part of the process of industrialization. Will pollution continue to increase without bound as more and more countries pass through the development phase or will it be controlled? (For earlier versions of this, see Malthus (1798) for renewable resources and the Club of Rome report (see Meadows, Meadows and Randers (1972)) for non-renewable resources). Intuitively, if 'clean air' is a normal good, we would expect that societies might be 'self-regulating' in the sense that as income increases, pollution controls also increase. However, this intution is somewhat misleading as the presence of external effects is an essential feature of environmental regulation.

A key question then is, do societies control pollution, or does it continually grow without bound as income grows? Recent empirical work suggests that, in fact, the output of many pollutants is controlled as income grows (for a discussion of the direct evidence on pollution controls and the level of pollution and international movements of pollution in response to these controls, see Grossman and Krueger (1991), Low and Yeats (1992), Lucas, Wheeler and Hettige (1992) and Levinson (1994)). Although the evidence is sketchy at this time (see Baumol and Oates (1979) for a discussion on this), it supports the view that, after passing through a period of high and increasing pollution, eventually, society takes actions to control these external effects. Several patterns emerge from the data. For some pollutants, the relationship between income and pollution follows an inverted $U$ while for others a 'sideways mirrored' $S$ (i.e., an inverted $U$ followed by a sustained increase) is seen (see World Bank (1993) and Grossman and Krueger (1995)).

The evidence cited above raises the question of what properties of the politico/economic process that determine environmental policies are essential for pollution to be controlled. Our goal in this paper is to present a simple theoretical model of this process for pollutants that are internal to a given political jurisdiction. To this end, we develop a model of the joint 
determination of the rate of development of the economy through market interactions and the extent of pollution regulation through collective decision making. We describe the time paths of pollution implied by alternative institutional arrangements and compare these to a planner's allocation. We show that depending on the collective decision making mechanism in place, the time path of pollution can display an inverted U shape, a "sideways mirrored" $S$, or an increasing (but bounded) level over time. The first two patterns fit well with the empirical evidence described above, while the last one coincides with the findings of the World Bank for some pollutants. In all cases, we show that the level of pollution is bounded along the equilibrium path.

A straightforward extension of the model shows that if the pollution is external to the political jurisdiction being modelled, the level of the pollutant will grow without bound. This suggests that some sort of political mechanism across countries is necessary to control these 'global' pollutants, but that once in place, this control will occur.

Although there is a large literature on the relationship between economic activity and the environment (see Baumol and Oates (1988) for a textbook treatment of the relevant static theory), there are few papers that explicitly model the relationship between growth and environmental degradation. In the endogenous growth literature the recent work by Fisher and van Marrejwijk (1994) and Mohtadi (1994) is closest to our own. Both these papers model the environment as an additional factor of production and concentrate on the impact of different criteria that a planner might choose to "allocate" this environmental input between households and firms. The key difference is that in our formulation, public policy is endogenously determined. In John, Pecchenino, Schimmelpfennig and Schreft (1994), the emphasis is on the analysis of the comparative statics properties of steady states of exogenous growth models in which the environment gets degraded by the act of consuming and resources can be used to improve it.

This paper also contributes to the literature, being developed in recent years, on both the large differences in income per capita across countries as well as the discrepancies in their 
growth rates. The class of models that have been developed covers the spectrum between those that rely on nonconvexities and multiple equilibria as sources of heterogeneity to those that ascribe most of the discrepancies to different policies. This latter category, for the most part, relies on unexplained differences in policies as sources of differences in performance. This paper tries to further our understanding by looking at a model in which policies are endogenously chosen and vary over time (see also Alesina and Rodrik (1994), Persson and Tabellini (1994), Glomm and Ravikumar (1992 and 1994) and Krusell, Quadrini and Rios-Rull (1995)). The motivation for doing this is that endogenous policies can result in non-balanced growth equilibrium paths even for standard convex environments; environments which --under constant policies-- would be characterized by balanced growth path equilibria. Thus, policy endogeneity provides an additional source of both heterogeneity and dynamics. In the model described in this paper, the equilibrium under taxation is such that the cross sectional relationship between growth rates and income levels displays an inverted $U$ shape. This theoretical implication, which is consistent with the findings of Easterly (1994) and Dongchul Cho (1995), provides an alternative interpretation to the standard view that such a relationship must be generated by models of nonconvexities and/or multiple equilibria: it is simply the --hard to predict ex-ante-dynamic behavior induced by collective decision making in an environment in which income effects matter.

The paper is organized as follws. Section 2 lays out the basic model, and studies the equilibrium in which individuals vote over pollution taxes. Section 3 more fully describes the dynamic behavior of such an equilibrium. Section 4 studies the case in which individuals vote over minimum quality or environmental standards. Section 5 presents a class of optimal allocations. Section 6 suggests some possible extensions and modifications, and section 7 offers some concluding comments.

\section{The Basic Model with Pollution Taxes}

We consider an economy that has available a wide range of productive techniques that differ 
according to both their costs of production and their environmental effects. The choice, by firms, among techniques is influenced not only by their price but also by restrictions on use imposed by the government. To model this aspect of firm decision making, we adopt the simplifying assumption that the government sets technique specific taxes with the aim of controlling pollution (in section 4, we consider the case in which the government institutes "minimum quality standards"). Interpreted broadly, however, these "environmental taxes" should be viewed as incorporating a wide array of regulations and other forms of control that result in an increase in the effective price of environmentally pernicious techniques.

We will use a growth model with two period lived overlapping generations. An implication of this is that voting decisions are made by individuals with short horizons, thus, the generational structure and the natural voting scheme that we study (more on this later) allow us to capture a realistic feature of actual economies. The use of the OLG formulation places some restrictions on the form that the growth model can take. In particular (see Boldrin (1992) and Jones and Manuelli (1992)), the simple one sector models of growth that have become popular in recent years do not generate growth without the inclusion of some form of external economy (Romer (1986)) or learning by doing externality (Stokey $(1988,1991)$ ). Since our objective is to analyze policies, it seems appropriate to use a model in which in the absence of pollution the competitive equilibrium is optimal and displays growth. For this reason, we will use a variation on the two sector model of growth (see Rebelo (1991) and Jones and Manuelli (1992)).

The supply side of the model is a two sector model with (potentially infinitely many) differentiated capital stocks. We assume that all forms or vintages of capital are perfect substitutes in production while they differ both in terms of cost of production and in how much pollution their use generates. In order to make the problem interesting we consider the case in which environmentally cleaner capital goods are more costly to produce.

This framework has the distinct advantage for the study of the relationship between output and environmental degradation that if the pollution generating activity is not productive, the resulting market allocation is efficient. Thus, we can effectively separate the issues of 
taxation to control environmental degradation from the benefits of corrective taxes in setups in which there are other sources of inefficiency (e.g., external economies of scale or learning by doing externalities).

The nature of pollution that we model is local in both the physical and temporal dimensions. We analyze a model in which voter's have full control over all polluting activities. Because of this, it is probably best to interpret our results as applying to pollution that is local in nature (i.e., restricted to the voting region). In the temporal sense we first consider the case in which the level of pollution produced at time $t$ affects only the members of generation $t-1$ without any direct generational spillovers. Although there are no direct effects, policy decisions on the part of one generation affect the well being of future generations through their impact on capital accumulation decisions.

We assume that successive generations play a voting game in taxes on polluting activity. At time $t$, individuals born at $t$ vote on pollution taxes that will be in effect during period $t+1$. Their realized utility, $\mathrm{V}_{\mathrm{t}}\left(\tau_{1}, \tau_{2}, \ldots\right)$, is the voter's utility function over consumption and pollution paths evaluated at a competitive equilibrium given the sequence of taxes. The function $V_{t}$ could (potentially) depend on the entire sequence of taxes chosen. We will examine subgame perfect equilibria of this voting game. As is well known, there are typically many equilibria in multiagent voting games. We consider a representative agent model, and simply select the equilibrium that corresponds to the best policy from the perspective of the representative agent. Even with this restriction, in general, very little can be said about the equilibrium outcomes of voting games of this type. Because of this, we will simplify the problem by going to a special OLG formulation. In essence, we will put enough restrictions on preferences and labor endowments so that $V_{t}$ depends only on current and past tax rates. Moreover, for our specification, it will be true that the only way that previously chosen taxes matter for an individual of generation $t$ is through their impact on the capital stock at the beginning of period t. In section 6 we discuss extensions to settings with heterogeneous agents.

To begin, we will describe the economic environment and the competitive equilibrium 
that results from an arbitrary sequence of taxes. This determines the form of $\mathrm{V}_{\mathrm{t}}$. We will then analyze the voting game given this indirect utility function over tax sequences.

\section{Preferences}

Consumer preferences are given by,

$$
\log c_{t}^{t}+\beta \log c_{t+1}^{t}-u\left(s_{t+1}\right)
$$

where $c_{j}^{i}$ is consumption in period $j$ of the individual born at time $i$ and $s_{i}$ is pollution in period $i$. We assume that individuals are endowed with one unit of labor in their first period of life and none in the second. Their endowments of all other goods are zero. Thus, individuals derive disutility from the level of pollution in their second period of life. Given the assumptions about voting, it is possible without changing the basic results to make preferences depend on the level of pollution when young if the separability assumption is maintained. We chose this simpler framework to simplify the presentation. We assume that $\mathrm{u}$ is increasing, convex and $\mathrm{C}^{2}$, and that $u^{\prime}(x) x$ is strictly increasing and $C^{\prime}$.

There is one feature of these preferences that is crucial for our derivations (although we suspect not for our results) and it is the independence of the level of saving from the rate of return. This independence implies that when deciding on the level of saving when they are young individuals do not have to take into account the impact of future taxes. This feature of the equilibrium guarantees that, as noted above, only current and past taxes will enter the voter's indirect utility function.

Consumers maximize utility by choosing consumption in each period of their lives taking after tax prices as given and beyond their control. It is standard to show that optimal decisions are completely summarized by a saving function which in this case is given by,

$$
b_{t}=(\beta /(1+\beta)) w_{t},
$$


where $w_{t}$ is the wage rate at time $t$ and $b_{t}$ is the level of savings.

First period consumption at time $t, c_{t}^{t}$, is $(1 /(1+\beta)) w_{t}$. If we denote the rate of interest between period $t$ and $t+1$ by $1+i_{t+1}$, second period consumption of an individual born at time $t$ is $c_{t+1}^{t}=\left(1+i_{t+1}\right)(\beta /(1+\beta)) w_{t}$.

\section{Production Side}

On the production side we assume that there is one consumption good produced at each date and a (potentially infinite) number of different capital goods. Throughout we assume that there is a large number of firms in each sector that behave competitively. The consumption good is produced using a composite capital good, $\mathrm{k}_{\mathrm{c}}$, and labor, $\mathrm{n}_{\mathrm{b}}$, according to the following production function,

$$
c_{t}=\mathrm{Bk}_{\mathrm{ct}}^{\alpha} n_{1}^{1-\alpha}
$$

where $\mathrm{k}_{\mathrm{ct}}=\int_{0}^{\infty} \mathrm{k}_{\mathrm{ct}}(\mathrm{z}) \mathrm{dz}$, and $\mathrm{k}_{\mathrm{ct}}(\mathrm{z})$ is the amount of capital of type $\mathrm{z}$ that is used in production of the consumption good. From a formal point of view, we allow firms to choose either finitely or infinitely many qualities of capital by modelling the choice of firms as a measure over z's. Due to the nature of the cost functions that we will use below, it will follow that in equilibrium, only one quality level will be chosen in any period.

This formulation implies that the different capital goods are perfect substitutes in production. This, in turn, implies that firms will only choose those varieties that have the lowest after tax rental rate. This after tax rental rate is given by,

$$
\hat{\mathbf{r}}_{\mathrm{kl}}(\mathrm{z})=\left(1+\tau_{\mathrm{t}}(\mathrm{z})\right) \mathbf{r}_{\mathrm{kt}}(\mathrm{z})
$$

where $r_{k s}(z)$ is the before tax rental rate for capital of type $z$ at time $t$ and $\tau_{t}(z)$ is the tax rate for using type $z$ capital at time $t$. Thus, a firm will choose to rent those varieties $z$ such that $\hat{r}_{k t}(z)$ is 
minimized.

To simplify, we consider a situation in which capital is fully malleable. At the beginning of the period the existing stock of capital, $\mathrm{k}_{\mathbf{l}}$, can be used to produce either capital goods of type $\mathrm{z}$ to be used in the consumption sector or to produce "generic" capital that will be used in the investment sector. Formally, the investment side of the economy can be summarized by

$$
\left\{\begin{array}{l}
\mathrm{k}_{\mathrm{t}}=\int_{0}^{\infty} \mathrm{m}(\mathrm{z}) \mathrm{k}_{\mathrm{ct}}(\mathrm{z}) \mathrm{dz}+\mathrm{x}_{\mathrm{t}} \\
\mathrm{k}_{\mathrm{t}+1}=(1-\delta)\left[\mathrm{k}_{\mathrm{ct}}+\mathrm{x}_{\mathrm{t}}\right]+A \mathrm{x}_{\mathrm{t}} .
\end{array}\right.
$$

The interpretation is that, at the beginning of time $t$, capital is split into consumption capital and investment capital. We assume that the production of new capital is linear in the capital goods allocated to the investment sector, $\mathrm{x}$--output of the investment sector is $\mathrm{Ax}_{\mathbf{t}}$. In this formulation, $m(z)$ is the amount of general capital (i.e., $k$ ) that is necessary to produce one unit of type $\mathrm{z}$ capital. Thus, the total amount of beginning of the period capital that is devoted to producing "consumption sector" capital is given by the integral $\int_{0}^{\infty} \mathrm{m}(\mathrm{z}) \mathrm{k}_{\mathrm{ct}}(\mathrm{z}) \mathrm{dz}$.

At the end of the period, both the stocks of capital that were used for investment production-- $\mathrm{x}_{\mathrm{t}}-$-and consumption capital-- $\mathrm{k}_{\mathrm{c}}$--are both depreciated at rate $\delta$, so capital at time $\mathrm{t}+$ 1 is $(1-\delta)\left[k_{c t}+x_{t}\right]+A x_{t}$. This formulation implicitly assumes that consumption capital left over reverts back to general capital at the end of the period on a one-for-one basis. Thus, the cost, $\mathrm{m}(\mathrm{z})$, of producing type $\mathrm{z}$ capital at time $\mathrm{t}$ should be understood as flow costs designed to attain a given level of cleanliness for just one period. We assume that $\mathrm{m}(\mathrm{z})$ is increasing in $\mathrm{z}$, convex and that $m(0)=1$. One implication of this formulation is that type $\mathrm{z}=0$ consumption capital and investment capital can be exchanged one for one. Thus, if we restricted quality choices to only be $\mathrm{z}=0$, we would have a standard two sector growth model. 
Firms in the investment sector use general capital --whose rental price we denote $\mathbf{r}_{\mathrm{II}^{-}}$- to produce capital available for use in the following period. The price of new capital is denoted $p_{k t}$. We assume that these firms behave as price takers and maximize profits.

In order to characterize the decision problem of the firms in the consumption sector and to make explicit how the choice of technology influences pollution we now describe the pollution generating process. What we have in mind is a situation in which goods are not clean or dirty "per se". Every good can be produced using "clean" and "dirty" technologies and it is the cost of producing the different technologies and the taxes associated with their use that will determine the equilibrium level of pollution. The simplest specification that captures this idea is one in which each capital good --indexed by z-- has a different pollution generating level per unit. This level is given by $\phi(\mathrm{z})$. Thus, the total amount of pollution at time $t$ is given by,

$$
\mathrm{s}_{\mathrm{t}}=\int_{0}^{\infty} \phi(\mathrm{z}) \mathrm{k}_{\mathrm{ct}}(\mathrm{z}) \mathrm{dz} .
$$

We assume that $\phi(z)$ is convex and decreasing so that higher index goods (higher quality) are less polluting. When combined with our assumption that the unit cost of production is increasing in $\mathrm{z}$ it follows that a cleaner technology can be used only at the expense of fewer goods produced. It is of course necessary to have some trade off between less polluting technologies and the ability of the economy to produce more output to avoid a trivial solution. As modeled, pollution has only "flow"effects; that is, decisions made by previous generations do not directly affect the amount of smoke breathed by generation $t$. This is restrictive and we discuss an extension to the case in which pollution is a cumulative or capital like variable in section 6.

In order to keep the collective decision about the level of taxes manageable it is useful to reduce the dimensionality of the tax schedule $\tau_{1}(z)$. A reasonable way of accomplishing this is to assume that the per unit of capital tax paid at time $t, \tau_{t}(z)$, is proportional to the amount of pollution produced, $\tau_{1}(\mathrm{z})=\tau_{\mathrm{t}} \phi(\mathrm{z})$. This implies that the after tax rental rate for $\mathrm{z}$ is, 


$$
(1+\tau, \phi(z)) r_{k t}(z)
$$

Finally, to keep the presentation simple we assume that the proceeds from this tax are wasted. In section 6 we discuss how the results would change under alternative uses of the tax revenue.

\section{Equilibrium}

For a given tax sequence $\left\{\tau_{t}\right\}$, the notion of equilibrium that we use is price taking equilibria. Formally we define an equilibrium by,

Definition: An equilibrium is a set of sequences $\left[c_{t}^{t-1}, c_{t}^{t}, k_{t+1}, z_{t}, s_{t}, k_{c t}(z), x_{t}, p_{k t}, r_{k t}(z), r_{t t}, 1+i_{t+1}, \tau_{t}\right.$ , t $\geq 0$ ], such that,

(i) For all $\mathrm{t} \geq 0, \mathrm{c}_{\mathrm{t}}^{\mathrm{t}}, \mathrm{c}_{\mathrm{t+1}}^{\mathrm{t}}$, solve the consumer's maximization problem,

(ii) $\mathrm{c}_{0}^{-1}$ is equal to $\mathrm{p}_{\mathrm{k} 0} \mathrm{k}_{0}$,

(iii) firms maximize profits,

(iv) $b_{t}=p_{k t} k_{t+1}$ (market clearing),

(v) $\left[p_{k t+1}(1-\delta)+r_{t t+1}\right] / p_{k t}=1+i_{t+1}$,

(vi) the tax $\tau_{t}$ is chosen, using a majority voting mechanism, by members of the generation born at t-1.

This definition does not require further elaboration except to point out that when making consumption-saving decisions individuals take as given all taxes, as well as the equilibrium level of pollution. Note, however, that separability of the utility derived from consumption and the disutility associated with environmental degradation guarantees that consumption-saving decisions are made independently of the level of pollution. Thus, there is some myopia that is built into our specification of preferences. It seems reasonable to assume that aggregate pollution should not be a large determinant of individual consumption and this is precisely what our formulation captures. 
We are now ready to describe the nature of the equilibrium. We first characterize the equilibrium for an arbitrary sequence of taxes, and then we study the endogenous determination of pollution taxes. Consider the pricing of the different capital goods. If we let $\mathbf{r}_{\mathrm{It}}$ be the rental rate for renting capital to use in the production of new capital $\left(x_{t}\right)$, profit maximization requires,

$$
\mathrm{r}_{\mathrm{kl}}(\mathrm{z}) \leq \mathrm{m}(\mathrm{z}) \mathrm{r}_{\mathrm{lt}}
$$

with equality if variety $\mathrm{z}$ is produced.

Consider next the decision of the capital producing firms. Let $\mathrm{p}_{\mathrm{kt}}$ be the price of new capital produced at time t. Since this is a constant returns to scale activity, the standard zero profit condition implies,

$$
\mathrm{r}_{\mathrm{it}} / \mathrm{A} \geq \mathrm{p}_{\mathrm{kt}}
$$

with equality if new capital is produced.

To complete the description of the implications of competitive behavior by firms we describe the equilibrium conditions satisfied by the firms in the consumption sector. First, as indicated before, it is necessary for these firms to choose which varieties of capital they will use. Given our assumptions about the form of the tax code, it follows that the firms in the consumption sector will choose the type (or types) of capital, $\mathbf{z}_{\mathfrak{l}}$, which solve:

(P1) $\quad \operatorname{minimize}_{\mathrm{z}} \hat{\mathrm{r}}_{\mathrm{kt}}(\mathrm{z})=$

$$
\begin{aligned}
& \left(1+\tau_{\mathrm{t}}(\mathrm{z})\right) \mathrm{r}_{\mathrm{kt}}(\mathrm{z})=\left(1+\tau_{\mathrm{t}} \phi(\mathrm{z})\right) \mathrm{r}_{\mathrm{kt}}(\mathrm{z}) \\
& =\left(1+\tau_{\mathrm{t}} \phi(\mathrm{z})\right) \mathrm{m}(\mathrm{z}) \mathrm{r}_{\mathrm{lt}} .
\end{aligned}
$$

Since $r_{\mathrm{It}}$ is independent of $\mathrm{z}$, this is equivalent to

$$
\left(P 1^{\prime}\right) \quad \min _{\mathrm{z}}\left(1+\tau_{\mathrm{t}} \phi(\mathrm{z})\right) \mathrm{m}(\mathrm{z})
$$


From now on we assume that this problem has a unique solution for each $\tau_{t}$. (We will shortly make assumptions that guarantee that this is the case.) This implies that only one variety will be used (and produced) in equilibrium at each date $t$.

For firms in the consumption sector, the rental price of capital (after taxes) must equal the marginal product of capital. That is:

$$
\begin{gathered}
\alpha B k_{\mathrm{ct}}\left(\mathrm{z}_{\mathrm{t}}\right)^{\alpha-1}=\hat{\mathrm{r}}_{\mathrm{kt}}\left(\mathrm{z}_{\mathrm{l}}\right)=\left(1+\tau_{\mathrm{t}} \phi\left(\mathrm{z}_{\mathrm{t}}\right)\right) \mathrm{r}_{\mathrm{kt}}\left(\mathrm{z}_{\mathrm{t}}\right) \\
=\left(1+\tau_{\mathrm{t}} \phi\left(\mathrm{z}_{\mathrm{t}}\right)\right) \mathrm{m}\left(\mathrm{z}_{\mathrm{t}}\right) \mathrm{r}_{\mathrm{lt}}
\end{gathered}
$$

Hence, using the equilibrium condition from the capital producing sector,

$$
\mathrm{p}_{\mathrm{kt}}=\frac{\mathrm{r}_{\mathrm{It}}}{\mathrm{A}}=\frac{1}{\mathrm{~A}} \frac{\alpha \mathrm{Bk_{ \textrm {ct } }}\left(\mathrm{z}_{\mathrm{t}}\right)^{\alpha-1}}{\left(1+\tau_{\mathrm{t}} \phi\left(\mathrm{z}_{\mathrm{t}}\right)\right) \mathrm{m}\left(\mathrm{z}_{\mathrm{t}}\right)}
$$

Finally, to close the model we need to specify the equilibrium condition that ties consumer decisions and producer decisions. We do this by imposing the equality of savings with the value of capital taken into period $t+1: b_{t}=p_{k k} k_{t+1}$. Using the equilibrium condition that the wage rate is given by the marginal product of labor, it follows that,

$$
p_{k t} k_{t+1}=\frac{\beta}{1+\beta} w_{t}
$$

and $w_{t}=(1-\alpha) B k_{c t}\left(z_{t}\right)^{\alpha}$

This, in turn, implies,

$$
\mathrm{k}_{\mathrm{t}+1} \frac{\alpha \beta \mathrm{B}}{\mathrm{A}} \frac{\mathrm{k}_{\mathrm{ct}}\left(\mathrm{z}_{\mathrm{t}}\right)^{\alpha-1}}{\left(1+\tau_{\mathrm{t}} \phi\left(\mathrm{z}_{\mathrm{t}}\right)\right) \mathrm{m}\left(\mathrm{z}_{\mathrm{t}}\right)}=\frac{(1-\alpha) \beta \mathrm{B}}{1+\beta} \mathrm{k}_{\mathrm{ct}}\left(\mathrm{z}_{\mathrm{t}}\right)^{\alpha}
$$


and hence

$$
\mathrm{k}_{\mathrm{ct}}\left(\mathrm{z}_{\mathrm{t}}\right)=\frac{\alpha}{1-\alpha} \frac{1+\beta}{\beta A} \frac{\mathrm{k}_{\mathrm{t}+1}}{\left(1+\tau_{\mathrm{t}} \phi\left(\mathrm{z}_{\mathrm{t}}\right) \mathrm{m}\left(\mathrm{z}_{\mathrm{t}}\right)\right.}
$$

Equation (2.10) summarizes the relationship between taxation, the level of future capital and the amount of capital allocated to the consumption sector. The positive effect of future capital on the capital allocated to the consumption sector captures the fact that the higher the level of $k_{t+1}$ the lower the price of capital at time $t$. This, in turn, reduces the amount used to produce new capital, $\mathbf{x}_{t}$, and , consequently, increases the amount of capital used in the consumption sector.

Also, $m\left(z_{t}\right) k_{c t}\left(z_{t}\right)+x_{t}=k_{t}$, so we can rewrite the law of motion for $k$ :

$$
\mathrm{k}_{\mathrm{t}+1}=(1-\delta+A) \mathbf{x}_{\mathrm{t}}+(1-\delta) \mathrm{k}_{\mathrm{ct}}\left(\mathrm{z}_{\mathrm{t}}\right)
$$

or,

$\mathbf{k}_{\mathrm{t}+1}=(1-\delta+A) \mathrm{k}_{\mathrm{t}}+\mathrm{k}_{\mathrm{ct}}\left(\mathrm{z}_{\mathrm{t}}\right)\left[(1-\delta)\left(1-\mathrm{m}\left(\mathrm{z}_{\mathrm{t}}\right)\right)-\operatorname{Am}\left(\mathrm{z}_{\mathrm{t}}\right)\right]$

Using (2.10) in the above gives,

$$
\mathrm{k}_{\mathrm{t}+1}=(1-\delta+A) \mathrm{k}_{\mathrm{t}}+\mathrm{k}_{\mathrm{t}+1} \frac{\alpha(1+\beta)\left[(1-\delta)\left(1-\mathrm{m}\left(\mathrm{z}_{\mathrm{t}}\right)\right)-\operatorname{Am}\left(\mathrm{z}_{\mathrm{t}}\right)\right]}{(1-\alpha) \beta A\left(1+\tau_{\mathrm{t}} \phi\left(\mathrm{z}_{\mathrm{t}}\right)\right) \mathrm{m}\left(\mathrm{z}_{\mathrm{t}}\right)}
$$

It follows that the growth rate of capital between time $t$ and $t+1$ depends on the tax rate chosen at time $t$. The precise expression is,

$$
\text { (2.12) } \gamma\left(\tau_{\mathrm{t}}\right)=\gamma_{\mathrm{kt}}=\frac{\mathrm{k}_{\mathrm{t}+1}}{\mathrm{k}_{\mathrm{t}}}=\frac{(1-\delta+\mathrm{A})}{1+\frac{\alpha(1+\beta)\left[(1-\delta)\left(\mathrm{m}\left(\mathrm{z}_{\mathrm{t}}\right)-1\right)+\operatorname{Am}\left(\mathrm{z}_{\mathrm{t}}\right)\right]}{(1-\alpha) \beta \mathrm{A}\left(1+\tau_{\mathrm{t}} \phi\left(\mathrm{z}_{\mathrm{t}}\right)\right) \mathrm{m}\left(\mathrm{z}_{\mathrm{t}}\right)}} \text {, }
$$


where the dependence of the equilibrium quality level, $z_{l}$, on the tax rate is described by (P. $\left.1^{\prime}\right)$. For future reference note that (2.10) and (2.12) imply that the equilibrium relationship between the level of capital in the consumption sector, $\mathrm{k}_{\mathrm{ct}}(\mathrm{z})$, and the contemporaneous level of aggregate capital, $\mathrm{k}_{\mathrm{t}}$, is given by,

$$
k_{c t}\left(z_{t}\right)=\frac{\alpha}{(1-\alpha)} \frac{(1+\beta)}{\beta A} \frac{(1-\delta+A) k_{t}}{\left(1+\tau_{t} \phi\left(z_{l}\right)\right) m\left(z_{l}\right)+\frac{\alpha}{(1-\alpha)} \frac{(1+\beta)}{\beta A}\left[(1-\delta)\left(m\left(z_{t}\right)-1\right)+A m\left(z_{t}\right)\right]}
$$

As expected, a higher level of initial capital results in a higher allocation of capital to the consumption sector. Anticipating the analysis that follow, higher taxes will result in higher quality capital goods used by the consumption sector. The effect of higher taxes in (2.13) is to increase the denominator and, hence, to reduce the amount of capital effectively used by the consumption sector of the economy.

Finally, we describe the factors that determine generation t's preferences over different $\tau_{t+1}$. Recall that members of generation $t$ vote on the pollution taxes that will be in place at time $t+1$. In doing so, voters are rational. By this we mean that they understand how taxes will affect all variables of the economy (i.e. they know the equilibrium relationship between taxes and prices and quantities) and, of course, how this affects their individual welfare. Since we have assumed away all heterogeneity within a generation the median voter result applies trivially: the equilibrium tax will be the tax that maximizes the welfare of each member of generation $t$.

There are two avenues through which taxes affect utility of an individual born at time $t$. First, note that consumption in their first period of life is independent of $\tau_{t+1}$. Second, consumption in their second period of life is equal to the rate of return times saving. But savings do not depend on the taxes they will choose. (It is at this point where the import of our assumption that saving is inelastic with respect to the interest rate becomes quite convenient.) Thus, if higher taxes at time $t+1$ hurt generation $t$ at all (and this is essential if we are to have a realistic model) it must be because they lower the rate of return between time $t$ and $t+1$. Finally, 
on the positive side, higher taxes will both increase the quality of capital goods used in the consumption sector at time $t+1$ and reduce the quantity of capital allocated to the consumption sector. This reduces the level of pollution that is consumed by this generation (see (2.4)).

How do taxes at time $t+1$ affect the rate of return? From the definition of equilibrium it follows that

$$
1+i_{t+1}=\frac{p_{k t+1}(1-\delta)+r_{I t+1}}{p_{k t}}
$$

Now, at the time of voting, $\mathrm{p}_{\mathbf{k t}}$ is fixed, independent of $\tau_{t+1}$ as can be seen from above. Moreover, $\mathrm{r}_{\mathrm{It}+1}=\mathrm{Ap}_{\mathrm{kl}+1}$ and hence,

$$
\left(1+i_{t+1}\right)=\frac{p_{k t+1}(1-\delta+A)}{p_{k t}}
$$

In this expression, the only thing that depends on $\tau_{t+1}$ is $p_{k t+1}$. Thus, the key channel through which taxes affect consumption of voters is through their impact on the unit price of capital.

To analyze the effect on pollution, from (2.4) and our characterization of the equilibrium it follows that,

$$
\mathbf{s}_{t+1}\left(\tau_{t+1}\right)=\phi\left(\mathrm{z}_{t+1}\left(\tau_{t+1}\right)\right)\left[\mathrm{k}_{\mathrm{ct+1}}\left(\mathrm{z}_{\mathrm{t}+1}\left(\tau_{t+1}\right)\right) / \mathrm{k}_{t+1}\right] \mathrm{k}_{t+1}=\mu\left(\tau_{t+1}\right) \mathrm{k}_{t+1}
$$

where anticipating some results we assume that $z_{t+1}$ will be a function of $\tau_{t+1}$.

To summarize this discussion, note that the indirect utility of voter's is given by: 


$$
V_{t}\left(\tau_{1}, \ldots\right)=\log c_{t}^{l}\left(\tau_{1}, \ldots\right)+\beta \log c_{t+1}^{t}\left(\tau_{1}, \ldots\right)-u\left(s_{t+1}\left(\tau_{1}, \ldots\right)\right)
$$

First, note that the effect of $\tau_{1}$ through $\tau_{t-1}$ on the voter's utility is completely summarized through their effect on $\mathbf{k}_{\mathbf{t}}$. Moreover, since all of these variables are predetermined and utility is separable, the term $\log c_{t}^{t}\left(\tau_{1}, \ldots\right)$ is independent of the voter's choice. For similar reasons, both $c_{t+1}^{t}\left(\tau_{1}, \ldots\right)$ and $s_{t+1}\left(\tau_{1}, \ldots\right)$ can be written as a function of $k_{t+1}$ and $\tau_{t+1}$ only. Finally, because of the independence of savings from the interest rate, it follows that $k_{t+1}$ does not depend on $\tau_{t+1}$. From all of this, it follows that the voter's problem is equivalent to maximizing

$$
\beta \log c_{t+1}^{t}\left(\tau_{t+1} ; k_{t+1}\right)-u\left(s_{t+1}\left(\tau_{t+1} ; k_{t+1}\right)\right)
$$

where $k_{t+1}$ is taken as given. Note that $c_{t+1}^{\prime}\left(\tau_{t+1} ; k_{t+1}\right)=p_{k t+1} k_{t+1}$. Because of our choice of log utility and the independence of $k_{t+1}$ from $\tau_{t+1}$, it follows that the voter's objective function is $V(\tau$, $\mathrm{k})$, which is given by,

$$
V(\tau, k)=\beta \log \left[p_{k}(\tau)\right]-u[\mu(\tau) k]
$$

where we have abused the notation slightly and explicitly indicated the dependence of the endogenous variables on the tax rate.

Even though it is possible to conduct the analysis at a fairly general level, the basic intutition can be fully captured in a simple setting in which we specialize the functions describing the flow cost of producing high quality goods, $\mathrm{m}(\mathrm{z})$, as well as the pollution per unit of capital z, $\phi(z)$. Specifically, we assume,

$$
\begin{aligned}
& m(z)=(1+z)^{\theta}, \theta>0 \text { and } \\
& \phi(z)=D(1+z)^{-v}, v>0
\end{aligned}
$$

We assume that $v>\theta \geq 1$. (Without this, the optimal choice of $z$ is 0 for all $\tau$.) Then, the determination of the optimal $z$ as a function of $\tau$ is given by problem (P.1') and summarized for 
this special case in the following proposition.

Proposition 1. The solution to problem (P.1') is given by $z(\tau)=0$ for $\tau \leq \tau_{L}$, and $z(\tau)=\left(\frac{(\nu-\theta) \tau D}{\theta}\right)^{1 / \nu}-1$, for $\tau \geq \tau_{L}$, where $\tau_{L}$ is given by $\tau_{L}=\theta /[(\nu-\theta) D]$.

Proof: The determination of the optimal quality as a function of the tax rate is given by the solution to,

$$
\begin{aligned}
\min _{z}(1 & +\tau \phi(z)) m(z) \\
& =\min _{z}\left(1+\tau D(1+z)^{-\eta}\right)(1+z)^{\theta} .
\end{aligned}
$$

The first order condition is,

$$
\begin{aligned}
& \theta(1+z)^{\theta-1}\left(1+\tau D(1+z)^{-v}\right)+(1+z)^{\theta}(-v) \tau D(1+z)^{-(v+1)} \\
& =(1+z)^{\theta-1}\left[\theta\left(1+\tau D(1+z)^{-v}\right)-v(1+z)^{-v} \tau D\right] .
\end{aligned}
$$

When $\tau=0$, this is $(1+z)^{\theta-1} \theta>0$, for all $z \geq 0$. This implies that $\mathrm{z}(\tau)=0$ for sufficiently small $\tau$, since the candidate interior solution yields a greater value of the objective function than the $\mathrm{z}=0$ solution. This candidate solution is a local minimum. Note that, as defined, $\tau_{L}$ satisfies,

$$
\left[\theta\left(1+\tau_{L} D\right)-\nu \tau_{L} D\right]=0
$$

For $\tau \geq \tau_{L}, \mathrm{z}$ is interior and given by the solution to,

$$
\theta+\theta \tau D(1+z)^{-v}=v \tau D(1+z)^{-v} .
$$

This condition implies, that $\mathrm{z}$ is given by, 


$$
z=\left(\frac{(v-\theta) \tau D}{\theta}\right)^{1 / v}-1
$$

Thus, Proposition 1 shows that for tax levels that fall short of $\tau_{L}$ there will be no impact on the equilibrium level of the quality of capital good chosen.

Our next goal is to use the result of Proposition 1 to determine $\mathrm{p}_{\mathrm{k}}$ and $\mu$ as functions of the tax rate given our choices of $\mathrm{m}$ and $\phi$. It turns out to be useful to introduce a variable that measures taxes relative to $\tau_{L}$. To this end define $y=\left(\tau / \tau_{L}\right)^{\theta / \nu}$. Thus, with this transformation, the functions of interest are (for a derivation, see the Appendix):

(2.16) $\mu(\mathrm{y})= \begin{cases}\mu_{1}(\mathrm{y})=\frac{\alpha(1+\beta)(1-\delta+A) D}{(1-\alpha) \beta A\left[\left(1+\frac{\theta}{v-\theta} y^{v / \theta}\right)+\frac{\alpha}{1-\alpha} \frac{1+\beta}{\beta}\right]} & \text { for } \mathrm{y} \leq 1 \\ \mu_{2}(y)=\frac{\alpha(1+\beta)(1-\delta+A) D y^{-v / \theta}}{(1-\alpha) \beta A\left[\left(1+\frac{\theta}{v-\theta}\right) y+\frac{\alpha}{1-\alpha} \frac{1+\beta}{\beta A}((1-\delta+A) y-(1-\delta))\right]} & \text { for } y \geq 1\end{cases}$

and,

$$
p_{k}(y)= \begin{cases}p_{k 1}(y)=K \frac{\left[\left(1+\frac{\theta}{v-\theta} y^{v / \theta}+\frac{\alpha}{1-\alpha} \frac{1+\beta}{\beta}\right]^{1-\alpha}\right.}{\left(1+\frac{\theta}{v-\theta} y^{v / \theta}\right.} & \text { for } y \leq 1 \\ p_{k 2}(y)=K \frac{\left[\left(1+\frac{\theta}{v-\theta}\right) y+\frac{\alpha}{1-\alpha} \frac{1+\beta}{\beta A}((1-\delta+A) y-(1-\delta))\right]^{1-\alpha}}{\left(1+\frac{\theta}{v-\theta}\right) y} & \text { for } y \geq 1\end{cases}
$$


where $\mathrm{K}$ is a constant.

There are several things to note about the equilibrium prices and quantities as a function of the tax rate. First, the price of capital, $p_{k}(y)$, varies with taxes (or in our case the variable $y$ ). For tax rates lower than $\tau_{L}(y<1)$ the function is decreasing in $y$. For values of $y \geq 1$ this function could be increasing although it eventually decreases. The possibility of an increasing region is interesting because it corresponds to a dominance of a waste effect: as higher qualities are produced and more resources are used up the price of the existing capital can increase. However, for very high levels of taxes, the substantial decrease in the demand for capital in the consumption sector eventually pushes its price downward. At $y=1$ (i.e. $\tau=\tau_{L}$ ), $p_{k}$ is not differentiable. The economic reason for this is simple: for low tax rates $(y<1)$, the level of the rate does influence the cost of capital in the consumption sector but does not induce any quality upgrades. In this region, firms in the consumption sector choose to use the lowest quality, since it is not efficient to upgrade. As the tax rate gets past the level $\tau_{L}$, firms not only demand less capital but also choose to use higher quality capital. Figure 1 shows two possible shapes for $\mathrm{p}_{\mathrm{k}}(\mathrm{y})$. One interesting thing to note is that in the case in which $\mathrm{p}_{\mathrm{k}}$ has an increasing region, $\mathrm{y}_{\mathrm{M}}$ corresponds to a form of monopoly price of capital as a function of $y$, conditional on the level of $y$ being greater than or equal to one. That is, in the region $\left[1, y_{M}\right]$ it is both the case that the value of capital increases and pollution per unit of capital $(\mu(y))$ decreases.

Second, pollution per unit of total capital, $\mu(\mathrm{y})$, is decreasing for all values of $y$. This function also displays a kink at $y=1$ corresponding to the quality upgrade. Finally, it is easy to verify that if policies are held constant (i.e. $y_{t}=y$ for all $t$ ) the equilibrium path it is of the balanced growth variety after just one period. Thus, if this model is to display more interesting dynamic behavior it must be because of the time varying nature of the equilibrium tax rates.

With this investment in notation it is now possible to establish some properties of the equilibrium choice of taxes (or, equivalently, $y$ ) as a function of predetermined variables. Given the nondifferentiability of some relevant functions at $y=1$ it is convenient to define the indirect 
voting function as,

$$
V(y, k)= \begin{cases}V_{1}(y, k) & \text { for } y \leq 1 \\ V_{2}(y, k) & \text { for } y \geq 1\end{cases}
$$

where $V_{i}(y, k) \equiv \ln \left(p_{k i}(y)\right)-u\left(\mu_{i}(y) k\right)$. The maximized value of $V$, denoted $V^{*}(k) \equiv V(y(k), k)$, where $y(k)$ is the optimal choice of y given $k$, is given by, $V^{*}(k)=\operatorname{Max}_{\{i=1,2\}} V_{i}^{*}(k)$. $V_{i}^{*}(k)$ is just the maximum of $V_{i}$ over the relevant domain for $y$, i.e. $0 \leq y \leq 1$ for $i=1$, and $y \geq 1$ for $I=2$. The maximizers are denoted $y_{1}(k)$ and $y_{2}(k)$, respectively. It follows that $V_{i}^{*}(k)=V_{i}\left(y_{i}(k), k\right)$, for $\mathrm{i}=1,2$.

We now show that for small values of $\mathrm{k}$--equivalently a low income per capita country-the equilibrium $\mathrm{y}$ is zero. As $\mathrm{k}$ increases, $\mathrm{y}$ increases, but stays in the region $\mathrm{y} \leq 1$. These two results simply formalize standard intuition: when income is very low --and consequently consumption is low-- the equilibrium choice of pollution tax is zero. As income increases --for higher values of $\mathrm{k}$-- the equilibrium level of taxes is positive but falls short of the minimum environmental tax $\tau_{\mathrm{L}}$. This induces a reallocation of capital between the two sectors but induces no (costly) quality upgrade. Finally, for sufficiently high levels of $k$, the equilibrium tax is greater than $\tau_{\mathrm{L}}$, and it grows without bound as a function of $\mathrm{k}$. The transition from the low tax region $(y \leq 1)$ to the high tax region $(y \geq 1)$ is not smooth. Specifically, we show that there exists a level of $k$, denoted $k_{F}$, such that $y(k)$ is discontinuous at $k_{F}$. The discontinuity is of a very simple form: y jumps upward at $\mathrm{k}_{\mathrm{F}}$. We postpone a more complete discussion of the economic intuition underlying this result until the next section.

In order to characterize the complete dynamic path of the equilibrium, it is useful to introduce an additional assumption to guarantee that, along the equilibrium path, $y$ will pass through the region $(0,1)$. Let $\zeta(y)$ be defined by, 


$$
\zeta(y)=\beta \alpha+\beta[\alpha(1+\beta) /(1-\alpha) \beta]\left[1+\theta /(\nu-\theta) y^{v / \theta}\right]^{-1}
$$

Let $\mathrm{k}_{\mathrm{A}}$ be the unique solution to $\zeta(1)=\mathrm{u}^{\prime}\left(\mu_{1}(1) \mathrm{k}_{\mathrm{A}}\right) \mu_{1}(1) \mathrm{k}_{\mathrm{A}}$, which clearly exists given our assumptions about $\mathrm{u}$.

Assumption A: There exists a $(\mathrm{k}, \mathrm{y})$ pair with $\mathrm{k}<\mathrm{k}_{\mathrm{A}}$ and $0 \leq \mathrm{y}<1$ such that,

$$
\zeta(y)<u^{\prime}\left(\mu_{1}(y) k\right) \mu_{1}(y) k .
$$

With this additional assumption we can now establish,

Proposition 2. If assumption A holds, the maximum of $V(y, k)$ is well defined for all $k \geq 0$. The maximizer, $y(k)$ has the following properties,

(i) $\exists \mathrm{k}_{\mathrm{B}}>0$, such that $\forall \mathrm{k} \leq \mathrm{k}_{\mathrm{B}}, \mathrm{y}(\mathrm{k})=\mathrm{y}_{1}(\mathrm{k})=0$,

(ii) $\exists k_{C}$ such that for all $k \geq k_{C}, y(k)=y_{2}(k)$ which is strictly increasing, continuous and $\lim _{\mathrm{k} \rightarrow \infty} \mathrm{y}(\mathrm{k})=\infty$,

(iii) For all $k, y_{2}(k)>y_{1}(k)$,

(iv) There exist $k_{D}$ and $k_{E}$ such that for all $k \in\left(k_{D}, k_{E}\right), y_{1}(k)$ is interior,

(v) If in addition to assumption $A, y_{1}(k)$ is differentiable, there exists a unique $k_{F}$ such that $y(k)=y_{1}(k)$ for $k \leq k_{F}$ and $y(k)=y_{2}(k)$ for $k \geq k_{F}$.

Remarks: Parts (i), (ii) and (iii) taken together imply that y has at least one upward jump. If the conditions for (v) hold, there is exactly one such discontinuity and y is weakly increasing everywhere. An implication of part (iv) is that if $\mathrm{y}=\mathrm{y}_{1}$ for some $\mathrm{k}$ in $\left(\mathrm{k}_{\mathrm{D}}, \mathrm{k}_{\mathrm{E}}\right)$, then the equilibrium tax rate induces no change in quality, but does change the composition of output between the consumption and investment sectors.

Even though we assume that $\mathrm{u}$ is convex, most of the analysis goes through as long as $\mathrm{u}$ is not 'too concave.' In particular, if $u=\log$, the equilibrium tax rate is independent of $k$ and 
pollution increases monotonically with income and the model converges in one period to a balanced growth path.

Proof: We first characterize $y_{1}(k)$ and $y_{2}(k)$.

Consider $\max _{0 \text { sys } 1} \mathrm{~V}_{1}(\mathrm{y}, \mathrm{k})$. Given that the function is continuous, existence and upperhemicontinuity of $y_{1}(k)$--the maximizer of $V_{1}$ in the region $[0,1]$ as a function of $k$-- follows from the maximum theorem. The function $V_{1}$ is differentiable and it can be checked that $\partial^{2} V_{1} / \partial y \partial k \geq 0$ (with the inequality being strict if $k>0$ ). Thus, the function is supermodular. The results of Topkis (1978) and Milgrom and Shannon (1994) show that the maximand $y_{1}$ is monotone increasing.

A straightforward calculation shows that,

$$
\partial V_{1} / \partial y=\left(\mu_{1}^{\prime} / \mu_{1}\right)\left[\beta\left(p_{k 1}^{\prime} / p_{k 1}\right)\left(\mu_{1} / \mu_{1}^{\prime}\right)-u^{\prime}\left(\mu_{1} k\right) \mu_{1} k\right]
$$

or, equivalently,

$$
\partial \mathrm{V}_{1} / \partial \mathrm{y}=\left(\mu_{1}^{\prime} / \mu_{1}\right)\left[\zeta-\mathrm{u}^{\prime}\left(\mu_{1} \mathrm{k}\right) \mu_{1} \mathrm{k}\right]
$$

where the argument $y$ is omitted when there is no risk of confusion. In this derivation we used the fact that $\beta\left(\mathrm{p}_{\mathrm{k} 1}^{\prime} / \mathrm{p}_{\mathrm{k} 1}\right)\left(\mu_{1} / \mu_{1}^{\prime}\right)=\zeta$, given the specific form of $\mathrm{p}_{\mathrm{k} 1}$ and $\mu_{1}$. Next consider,

$$
\mathrm{H}(\mathrm{k})=\max _{0 \leq y \leq 1}\left\{\zeta(\mathrm{y})-\mathrm{u}^{\prime}\left(\mu_{1}(\mathrm{y}) \mathrm{k}\right) \mu_{1}(\mathrm{y}) \mathrm{k}\right\}
$$

It follows that $\lim _{k \rightarrow 0} H(k)>0$, and $\lim _{k \rightarrow \infty} H(k)<0$. Thus, there exists some $k_{B 1}$ such that $k \leq k_{B 1}$ implies $H(k) \geq 0$. Since $\partial V_{1} / \partial y \leq\left(\mu_{1}^{\prime} / \mu_{1}\right) H(k)$, this implies $y_{1}(k)=0$ for $k \leq k_{B 1}$. We will later show that $\mathrm{y}_{1}$ and $\mathrm{y}$ coincide on an interval $\left[0, \mathrm{k}_{\mathrm{B}}\right]$ with $\mathrm{k}_{\mathrm{B}} \leq \mathrm{k}_{\mathrm{B} 1}$.

Note that as defined in Assumption $\mathrm{A}, \mathrm{k}_{\mathrm{A}}$ is the smallest $\mathrm{k}$ such that $\mathrm{y}_{1}(\mathrm{k})$ is one. Given 
the monotonicity result it is also equal to one for $k \geq k_{A}$. That $k_{B 1}<k_{A}$ is simply guaranteed by Assumption A. In Figure 2 we show a candidate $y_{1}(k)$ function.

We now characterize the solution, $y_{2}(k)$, to the $\max$ of $V_{2}$. We need to consider two cases. If $y_{M}>1$ the function $V_{2}$ is clearly increasing in the region $\left[1, y_{M}\right]$. Thus in this case $y_{2}>y_{M}$. From an economic point of view $y_{M}$ is a monopoly price of capital and the old would never choose taxes that result in a price lower than this monopoly price. The second case is when $\mathrm{y}_{\mathrm{M}}=1$. This corresponds to a $\mathrm{p}_{\mathrm{k} 2}$ function that is decreasing. In this case define $\mathrm{k}_{\mathrm{Cl}}$ as the largest value of $k$ such that $y_{2}(k)=1$. Using the first order conditions for the maximization of $V_{2}$, one gets,

$$
\partial \mathrm{V}_{2} / \partial \mathrm{y}=\left(\mu_{2}^{\prime} / \mu_{2}\right)\left[\beta\left(\mathrm{p}_{\mathrm{k} 2}^{\prime} / \mathrm{p}_{\mathrm{k} 2}\right)\left(\mu_{2} / \mu_{2}^{\prime}\right)-\mathrm{u}^{\prime}\left(\mu_{2} \mathrm{k}\right) \mu_{2} \mathrm{k}\right]
$$

Then, $\mathrm{k}_{\mathrm{Cl}}$ satisfies,

$$
\beta\left(\mathrm{p}_{\mathrm{k} 2}^{\prime}(1) / \mathrm{p}_{\mathrm{k} 2}(1)\right)\left(\mu_{2}(1) / \mu_{2}^{\prime}(1)\right)=\mathrm{u}^{\prime}\left(\mu_{2}(1) \mathrm{k}_{\mathrm{C} 1}\right) \mu_{2}(1) \mathrm{k}_{\mathrm{Cl}}
$$

It is easy to show that $V_{2}$ is supermodular as well and hence that $y_{2}$ is increasing. Moreover, inspection of the function $\beta\left(\mathrm{p}_{\mathrm{k} 2}^{\prime}(\mathrm{y}) / \mathrm{p}_{\mathrm{k} 2}(\mathrm{y})\right)\left(\mu_{2}(\mathrm{y}) / \mu_{2}^{\prime}(\mathrm{y})\right)$ shows that it is monotone increasing for $y \geq y_{M}$ ( $y \geq 1$ when $p_{k 2}$ is everywhere decreasing), while $u^{\prime}\left(\mu_{2}(y) k\right) \mu_{2}(y) k$ is decreasing. Since equality of these two functions is a necessary condition for an interior maximum $(y>1)$ it follows that the maximizer is unique and hence continuous. Two possible $y_{2}$ functions --depending on whether $y_{M}>1$ or $y_{M}=1--$ are shown in Figure 2. Simple inspection implies that $\mathrm{y}_{2}(\mathrm{k}) \rightarrow \infty$ as $\mathrm{k} \rightarrow \infty$.

We will now prove (iii).

We show that $\mathrm{k}_{\mathrm{C} 1}<\mathrm{k}_{\mathrm{B} 1}$. Direct calcualtion shows that $\mathrm{p}_{\mathrm{k} 2}^{\prime}(1)>\mathrm{p}_{\mathrm{k} 1}(1)$. From the definition of $\mathrm{k}_{\mathrm{C} 1}$ and $\mathrm{k}_{\mathrm{B} 1}$ and given that the functions $\mathrm{p}_{\mathrm{ki}}$ and $\mu_{\mathrm{i}}$ are continuous at 1 , it follows that, 


$$
\mu_{2}^{\prime}(1) \mathrm{u}^{\prime}\left(\mu_{2}(1) \mathrm{k}_{\mathrm{C} 1}\right) \mu_{2}(1) \mathrm{k}_{\mathrm{C} 1}>\mu_{1}^{\prime}(1) \mathrm{u}^{\prime}\left(\mu_{1}(1) \mathrm{k}_{\mathrm{B} 1}\right) \mu_{1}(1) \mathrm{k}_{\mathrm{B} 1}
$$

Direct calculation shows that $\mu_{2}^{\prime}(1)<\mu_{1}^{\prime}(1)<0$. Thus,

$$
\mu_{2}^{\prime}(1) \mathrm{u}^{\prime}\left(\mu_{2}(1) \mathrm{k}_{\mathrm{Cl}}\right) \mu_{2}(1) \mathrm{k}_{\mathrm{Cl}}>\mu_{1}^{\prime}(1) \mathrm{u}^{\prime}\left(\mu_{1}(1) \mathrm{k}_{\mathrm{B} 1}\right) \mu_{1}(1) \mathrm{k}_{\mathrm{B} 1}>\mu_{2}^{\prime}(1) \mathrm{u}^{\prime}\left(\mu_{1}(1) \mathrm{k}_{\mathrm{B} 1}\right) \mu_{1}(1) \mathrm{k}_{\mathrm{B} 1},
$$

and this implies,

$$
\mathrm{u}^{\prime}\left(\mu_{2}(1) \mathrm{k}_{\mathrm{Cl}}\right) \mu_{2}(1) \mathrm{k}_{\mathrm{Cl}}<\mathrm{u}^{\prime}\left(\mu_{\mathrm{I}}(1) \mathrm{k}_{\mathrm{B} 1}\right) \mu_{1}(1) \mathrm{k}_{\mathrm{B} 1}
$$

Given the monotonicity of $\mathrm{u}^{\prime}(\mathrm{x}) \mathrm{x}$ this implies $\mathrm{k}_{\mathrm{Cl}}<\mathrm{k}_{\mathrm{B} 1}$.

The key feature of the functions $y_{i}$ in Figure 2 is that they do not intersect. Thus, if for some values of $k$ the function $V$ equals $V_{1}$ while for others $V$ equals $V_{2}$ then at the switch points there will be a discontinuity in $y(k)$. In particular, if as $k$ increases the optimum switches from $V_{1}$ to $V_{2}$, then $y(k)$ will display an upward jump. In Figure 2 such a $k$ is denoted $k_{F}$ (the location is somewhat arbitrary).

To complete the argument we need to show that for low values of $k, V_{1}^{*}>V_{2}^{*}$, while the opposite holds for large values of $k$ (this is parts (i) and (ii)). First we show that for small $k$, $\mathrm{V}_{1}^{*}>\mathrm{V}_{2}^{*}$. Let $\mathrm{k} \leq \min \left\{\mathrm{k}_{\mathrm{B} 1}, \mathrm{k}_{\mathrm{Cl}}\right\}$. Then,

$$
V_{1}^{*}(k)=V_{1}(0, k) \text { and } V_{2}^{*}(k)=V_{2}(1, k)
$$

Thus, using the fact that $\mathrm{p}_{\mathrm{k} 1}(1)=\mathrm{p}_{\mathrm{k} 2}(1)$, we get,

$$
\mathrm{V}_{1}^{*}-\mathrm{V}_{2}^{*}=\beta \ln \left(\mathrm{p}_{\mathrm{k} 1}(0) / \mathrm{p}_{\mathrm{k} 1}(1)\right)-\left[\mathrm{u}\left(\mu_{1}(0) \mathrm{k}\right)-\mathrm{u}\left(\mu_{2}(1) \mathrm{k}\right)\right]
$$

Note that the first term is strictly positive, while the second converges to zero as $\mathrm{k}$ goes to zero. This completes the argument that $y=y_{1}$ for small $k$. Define $k_{B}$ as the largest such $k$. 
Next we show $V_{2}^{*}>V_{1}^{*}$ for $k$ large. Let $k>\max \left\{k_{A}, k_{C l}\right\}$, and such that $y_{2}(k)>y^{*}>1$, and $y_{1}(k)=1$ (see Figure 2). Hence $V_{2}(y, k)>V_{2}\left(y^{*}, k\right)$. Thus,

$$
\mathrm{V}_{2}^{*}-\mathrm{V}_{1}^{*} \geq \mathrm{V}_{2}\left(\mathrm{y}^{*}, \mathrm{k}\right)-\mathrm{V}_{1}(1, \mathrm{k})=\beta \ln \left(\mathrm{p}_{\mathrm{k} 2}\left(\mathrm{y}^{*}\right) / \mathrm{p}_{\mathrm{k} 2}(1)\right)-\left[\mathrm{u}\left(\mu_{2}\left(\mathrm{y}^{*}\right) \mathrm{k}\right)-\mathrm{u}\left(\mu_{1}(1) \mathrm{k}\right)\right]
$$

Since the first term is bounded, it suffices to show that the second term (in square brackets) goes to $-\infty$ as $k$ grows. Since $u$ is convex it follows that,

$$
\mathrm{u}\left(\mu_{1}(1) \mathrm{k}\right)-\mathrm{u}\left(\mu_{2}\left(\mathrm{y}^{*}\right) \mathrm{k}\right) \geq \mathrm{u}^{\prime}\left(\mu_{2}\left(\mathrm{y}^{*}\right) \mathrm{k}\right) \mu_{2}\left(\mathrm{y}^{*}\right) \mathrm{k}\left[\left(\mu_{2}\left(\mathrm{y}^{*}\right)-\mu_{1}(1)\right) / \mu_{2}\left(\mathrm{y}^{*}\right)\right]
$$

and the result now follows from our assumption about $\mathrm{u}^{\prime}(\mathrm{x}) \mathrm{x}$ converging to $\infty$ as $\mathrm{x}$ goes to $\infty$.

This completes the proof of parts (i) and (ii).

To prove part (iv), consider the first order condition for an interior maximum of $\mathrm{V}_{1}$. It is given by,

$$
\partial V_{1} / \partial y=\left(\mu_{1}^{\prime}(y) / \mu_{1}(y)\right)\left[\zeta(y)-u^{\prime}\left(\mu_{1}(y) k\right) \mu_{1}(y) k\right]=0
$$

It is sufficient to show that for some $\mathrm{k}$ and $\mathrm{y}$, the term in square brackets is zero. From assumption $\mathrm{A}$, this term is negative for some $\mathrm{k}<\mathrm{k}_{\mathrm{A}}$ and some $\mathrm{y}<1$. It is positive when evaluated at $y=1$ for this $k$. It follows that for this $\mathrm{k}$, this term is zero for some $\mathrm{y}$ in $(0,1)$. By continuity of $u^{\prime}$, it follows that this holds for an open set of k's.

To prove part (v), note that it is sufficient to show that if at some $k, y(k)=y_{2}(k)$, then, $y\left(k^{\prime}\right)=y_{2}\left(k^{\prime}\right)$ for all $k^{\prime}>k$. To see that this holds, it is sufficient to show that $V_{2}^{* \prime}>V_{1}^{* \prime}$ for all $k$. To see that this holds, recall that $V_{i}^{*}=V_{i}\left(y_{i}(k) ; k\right)$ and so $V_{i}^{*}=\partial V_{i}(y ; k) / \partial y d y_{i} / d k+\partial V_{i}(y ; k) / \partial k$. By the definition of $y_{i}$, it follows that the first term is zero and hence it is sufficient to show that $\partial V_{2}(y ; k) / \partial k>\partial V_{1}(y ; k) / \partial k$. Straightforward calculations show that this is equivalent to showing that $\mu_{1}\left(y_{1}(k)\right)>\mu_{2}\left(y_{2}(k)\right)$ for all $k$. That this holds follows from the fact that both $\mu_{1}$ and $\mu_{2}$ are 
monotonically decreasing and they are equal at $y=1$.

Even though Proposition 2 contains the basic result, it is useful to more carefully analyze what kind of time path for taxes and pollution are implied by it. We now turn to that task.

\section{The Dynamics on the Equilibrium Path}

It is of interest to analyze what kind of time paths for income and pollution --the variables selected by Grossman and Krueger-- are implied by this model. First, consider how the growth rate of total basic capital depends on the tax rate or, more precisely, on y. From (2.12) and using the specific functional forms for the example it is possible to show that $\gamma(y)$--the growth rate of basic capital is given by,

$$
\gamma(\mathrm{y})=\left\{\begin{array}{cl}
\frac{(1-\delta+A)\left(1+\frac{\theta}{v-\theta} y^{v / \theta}\right)}{\left(1+\frac{\theta}{v-\theta} y^{v / \theta}\right)+\frac{\alpha}{1-\alpha} \frac{1+\beta}{\beta}} & \text { for } \mathrm{y} \leq 1 \\
\frac{(1-\delta+A)\left(1+\frac{\theta}{v-\theta}\right) y}{\left(1+\frac{\theta}{v-\theta}\right) y+\frac{\alpha}{1-\alpha} \frac{1+\beta}{\beta A}((1-\delta+A) y-(1-\delta))} & \text { for } \mathrm{y} \geq 1
\end{array}\right.
$$

It follows from (3.1) that the growth rate is increasing for values of $\tau$ that fall short of $\tau_{L}$ $(y<1)$, while it is decreasing for values of $\tau>\tau_{L}(y>1)$. Under some parameter restrictions, it follows that $\lim _{\mathrm{y} \rightarrow \infty} \gamma(\mathrm{y})$ is both greater than one (which implies positive asymptotic growth) as 
well as less than $\gamma(0)$. The intuition underlying this result is simple: for small values of $y(y \leq 1)$ a tax increase induces a "reallocation effect" as more capital is devoted to investment and less to the production of consumption goods (which is the activity that is taxed). This, of course, increases the growth rate. In the region $y \geq 1$, the higher level of taxes results in higher quality capital goods being demanded by the consumption sector (in smaller quantities though).

Production of cleaner capital goods is a resource using activity and the net result is that the allocation of capital to the investment sector is decreased with the resulting negative effect on the growth rate. An example of the function $\gamma(y)$ is shown in Figure 3.

What are the time paths of pollution and income? First, note that our assumptions about the parameters governing the growth rate of capital imply that on an equilibrium path the stock of basic capital is increasing and converges to infinity. Next, income is given by,

$$
\mathrm{I}(\mathrm{y})=\mathrm{B}\left(\mathrm{k}_{\mathrm{c}}(\mathrm{y}) / \mathrm{k}\right)^{\alpha} \mathrm{k}^{\alpha}\left[1+\alpha\left(\mathrm{k} / \mathrm{k}_{\mathrm{c}}(\mathrm{y})-\mathrm{m}(\mathrm{y})\right)\right]
$$

It is possible to show that a jump in y decreases total income. Finally, pollution is given by $s(y)=\mu(y) k$, which is decreasing in $y$ and increasing in $\mathrm{k}$.

Under the assumptions that guarantee that $\gamma(\mathrm{y})>\gamma(\infty)$ for all $\mathrm{y}$, it is relatively simple to study the time path of the endogenous variables in this economy: they are given by the mapping from the stock of capital $k$ to the variable of interest as the latter is an increasing (because the growth rate is strictly bounded above one) function of time. We summarize the main results in the following proposition,

Proposition 3: Assume A, and that $\gamma(y)>\gamma(\infty)>1$ for all $y$. Then, for a given initial capital $\mathrm{k}_{0}$ which is assumed small,

(i) There is some $t_{0}^{*}$ such that for $0 \leq t \leq t_{0}^{*}$ :

(a) the equilibrium tax rate $y_{t}$ is zero,

(b) the growth rate is constant and equal to $\gamma(0)$, 
(c) pollution is increasing.

(ii) There is a $t_{1}^{*}>t_{0}^{*}$, such that for all $t$ between $t_{0}^{*}$ and $t_{1}^{*}$ :

(a) the equilibrium tax rate is increasing, but $y_{1} \leq 1$,

(b) the growth rate is increasing over time,

(c) the level of pollution is decreasing.

(iii) At $\mathrm{t}=\mathrm{t}_{1}^{*}$,

(a) the equilibrium tax rate jumps up to a value $y>1$,

(b) the level of pollution jumps down.

(iv) For $\mathrm{t}>\mathrm{t}_{1}^{*}$,

(a) the level of pollution increases over time and converges to $s_{\tau}^{*}$, where $s_{\tau}^{*}$ satisfies,

$$
u^{\prime}\left(s_{\tau}^{*}\right) s_{\tau}^{*}=\beta \alpha /(1+v / \theta),
$$

(b) the tax rate is increasing over time and converges to $\infty$,

(c) the asymptotic growth rate of consumption, $\gamma_{c}(\infty)$, is strictly greater than one.

Proof: First, note that as the growth rate is strictly positive the stock of capital is monotonically increasing over time. Consider (i). From Proposition 2 if $k_{0}<k_{A}$, the optimal $y(k)$ is zero. Thus, in this region, taxes are zero and growth is given by $\gamma(0)$. Pollution is increasing and it can be verified that the ratio of $s_{t}$ to $I_{t}$--where $I$ is income-- is constant.

(ii) Even if the economy starts with $\mathrm{k}_{0}<\mathrm{k}_{\mathrm{A}}$ a positive growth rate of capital implies that eventually the capital stock reaches $\mathrm{k}_{\mathrm{A}}$. At that point taxes start to increase smoothly (although they remain strictly below one) and the growth rate of capital increases (see in Figure 3 the region $0<y<1$ ). From Propostion 2, the first order condition for an interior solution is,

$$
\zeta\left(y_{t}\right)=u^{\prime}\left(\mu_{1}\left(y_{t}\right) k_{t}\right) \mu_{1}\left(y_{t}\right) k_{t},
$$

or, equivalently,

$$
\zeta\left(\mathrm{y}_{\mathrm{t}}\right)=\mathrm{u}^{\prime}\left(\mathrm{s}_{\mathrm{t}}\right) \mathrm{s}_{\mathrm{t}}
$$


but, from the definition of $\zeta\left(y_{t}\right)$ (see Assumption $A$ ) it is a decreasing function of $y$, and $y$ is increasing in $\mathrm{t}$. Thus, in this region, $\zeta\left(\mathrm{y}_{\mathrm{t}}\right)$ is decreasing. Given our monotonicity assumption on $\mathrm{u}^{\prime}(\mathrm{x}) \mathrm{x}$ it follows that $\mathrm{s}_{\mathrm{t}}$ must be decreasing.

(iii) When the capital stock reaches $k_{F}$ (see Proposition 2) there is a regime switch and taxes jump upwards. Since the level of pollution is given by $s_{t}=\mu\left(y_{t}\right) k_{t}$, it must discontinuously decrease.

(iv) After the capital stock gets past the value $k_{F}, y_{2}(k)$--and hence $y(k)--$ is increasing. More specifically, from the proof of Proposition 2 it follows that $y_{t}$ solves,

$$
\eta\left(y_{t}\right) \equiv \beta\left(p_{k 2}^{\prime}\left(y_{t}\right) / p_{k 2}\left(y_{t}\right)\right)\left(\mu_{2}\left(y_{t}\right) / \mu_{2}^{\prime}\left(y_{t}\right)\right)=u^{\prime}\left(\mu_{2}\left(y_{t}\right) k_{t}\right) \mu_{2}\left(y_{t}\right) k_{1}
$$

Direct calculation shows that $\eta\left(y_{t}\right)$ is continuous, monotone increasing and satisfies $\lim _{y \rightarrow \infty} \eta(y)=\beta \alpha /(1+v / \theta)$. It follows from this equation (as well as from Proposition 2) that $y_{t}$ is increasing (it is increasing in $k_{t}$ and $k_{1}$ is increasing over time). To show that it goes to o suppose to the contrary that it converges to some value $y^{*}$. This generates a contradiction in (3.3) as $t$ goes to $\infty$, since the left hand side converges to $\eta\left(y^{*}\right)$, while the right hand side goes to $\infty$.

To study the behavior of pollution rewrite (3.3) as,

$$
\eta\left(y_{t}\right)=u^{\prime}\left(s_{t}\right) s .
$$

Since $\eta\left(y_{t}\right)$ is increasing, so is $s_{t^{*}}$ Given that $\eta\left(y_{t}\right)$ converges to $\beta \alpha /(1+v / \theta)$, it follows that the limiting level of pollution also satisfies

$$
u^{\prime}\left(s_{\mathfrak{t}}^{*}\right) s_{\mathfrak{\tau}}^{*}=\beta \alpha /(1+v / \theta)
$$

Finally, consider the growth rate of consumption, $\gamma_{\mathrm{ct}}$. From the production function it follows that $\gamma_{\mathrm{ct}}=\left(\gamma_{\mathrm{kct}}\right)^{\alpha}$, where $\gamma_{\mathrm{kct}}$ is the growth rate of capital used in the consumption sector. 
From equation (2.13) (using the specific forms of $m$ and $\phi$ ) one gets,

$$
\gamma_{\mathrm{kct}}=\gamma_{\mathrm{kt}}\left(\gamma_{\mathrm{yt}}\right)^{-1},
$$

where $\gamma_{k t}$ is the growth rate of the capital stock, and $\gamma_{y t}$ is the growth rate of taxes.

From the defintion of $\mathrm{s}_{\mathrm{t}}$, after the equlibrium values of all functions have been substituted in, we get,

$$
\gamma_{\mathrm{kct}}=\gamma_{\mathrm{st}}\left(\gamma_{\mathrm{yt}}\right)^{\mathrm{v} / \theta}
$$

From these two equations it follows that

$$
\gamma_{\mathrm{kt}}\left(\gamma_{\mathrm{yt}}\right)^{-1}=\gamma_{\mathrm{st}}\left(\gamma_{\mathrm{yt}}\right)^{\mathrm{v} / \theta},
$$

where $\gamma_{\mathrm{st}}$ is the growth rate of pollution.

Let a starred variable denote the limit as $t \rightarrow \infty$ of any of these growth rates. It follows that,

$$
\gamma_{\mathrm{k}}^{*}=1 \mathrm{x}\left(\gamma_{\mathrm{y}}^{*}\right)^{(\mathrm{v} / \theta+1)},
$$

since asymptotically $\mathrm{s}_{\mathrm{t}}$ does not grow.

It follows that,

$$
\gamma_{\mathrm{kc}}^{*}=\gamma_{\mathrm{k}}^{* 1 /(v / \theta+1)}>1 .
$$

This, of course, implies that the limiting growth rate of consumption is positive. 
An interesting implication of this Proposition is that the time path of pollution is not monotone. An example is shown in Figure 4. After an initial period in which pollution increases and taxes are zero, there is a period of relatively low taxes, no quality upgrades and decreases in the level of pollution. This is followed by a period in which taxes jump, and the much higher level of taxes induces quality upgrades. However, after the initial decrease in pollution, there is a steady increase to a steady state. Without further assumptions it is not possible to determine whether $s_{\tau}^{*}$ is higher or lower than the level $s_{t}$ at $t_{0}^{*}$. This very simple model has the ability to capture the inverted $U$ shape at relatively low levels of income as well a a tendency for pollution to increase to increase afterwards --the sideways $S$ pattern. The time path of growth rates of the capital stock is also quite interesting: after an initial period of relatively high and constant growth rates there follows a period of increasing growth rates -- a growth boom-- (this corresponds to the period of increased taxation and no quality upgrades) which, in turn, is followed by a long run decline of growth rates.

\section{Regulating Quality Choice}

An alternative institution that can be used to enforce environmental standards are quantitative restrictions. For example, in the U.S. there is a quantitative restriction on the number of leaded gasoline burning car engines that can be sold: it is zero. This type of quantitative restriction is common in many environmental regulations. One way of modelling quantitative restrictions is to allow the voters at time $t$ to collectively choose a minimum level of quality $z$. In other words, at time $t$ the old vote on a level of quality $z_{t}$ and firms cannot use any variety $z$, with $z<z_{t}$. (Alternatively, one can interpret this scheme as a different simplification of the tax rules where $\tau=\infty$ for all $\mathrm{z}<\mathrm{z}_{\tau}$, for some $\mathrm{z}_{\tau}$, and $\tau=0$ for $\mathrm{z} \geq \mathrm{z}_{\tau}$.) It turns out that the equations describing the equilibrium for a given value of the tax rates hold with $\tau_{t}$ equal to zero. The reason for this is simple: if the policy specifies that the lowest available quality is $z_{t}$, then firms will choose capital of quality exactly equal to $\mathrm{z}_{\mathrm{t}}$ since all forms of capital are perfect substitutes. The market price of capital will be $m\left(z_{t}\right) r_{I t}$, and firms optimize taking this as given.

It is useful to describe how the key variables vary with $\mathrm{z}$. First, consider the price of 
capital. Simple calculations using (2.9) and (2.13) show that $\mathrm{p}_{\mathrm{kq}}(\mathrm{z})$ (here the subindex $\mathrm{q}$ indicates that the collective decision is over qualities) is given by,

$$
p_{k q}(z)=M k^{\alpha-1}\left[a_{0} m(z)-a_{1}\right]^{1-\alpha} / m(z),
$$

where $a_{0}=1+[\alpha(1+\beta)(1-\delta+A)] /[(1-\alpha) \beta A], a_{1}=\alpha(1+\beta)(1-\delta) /[(1-\alpha) \beta A]$, and $M=\left(a_{0}-1\right) \alpha B / A$. If $a_{1} / \alpha a_{0}>1$, denote by $z_{M}$ the value of $z$ satisfying $m\left(z_{M}\right)=a_{1} / \alpha a_{0}$. If $a_{1} / \alpha a_{0} \leq 1$, set $z_{M}=0$. As in the case in which the collective decision making is over taxes, there is a value of the policy variable --which we denote $\mathrm{z}_{\mathrm{M}^{-}}$- that maximizes the value of capital and, hence, the value of consumption of the voters --the old. Note that in equilibrium the minimum allowable quality level will be always at least equal to $z_{M}$. It can be easily verified the the function $p_{k q}(z)$ is decreasing for $z \geq \mathbf{z}_{\mathrm{M}}$. In order to avoid unnecessary notation, we will concentrate on the case $\mathrm{z}_{\mathrm{M}}=0$.

The amount of pollution per unit of total capital is given by,

$$
\mu_{q}(z)=D\left(a_{0}-1\right)\left[(1+z)^{v}\left(a_{0} m(z)-a_{1}\right)\right]^{-1}
$$

This function is strictly decreasing for all z's. Thus, the higher the minimum quality level the lower the amount of pollution per unit of output.

In this case, the rate of growth in total capital is given by the appropriate version of (2.12). It is given by,

$$
\gamma_{\mathrm{kq}}(\mathrm{z})=(1-\delta+A)\left[1+\left(\mathrm{a}_{0} \mathrm{~m}(\mathrm{z})-\mathrm{a}_{1}\right) / \mathrm{m}(\mathrm{z})\right]^{-1}
$$

which is decreasing for all $z$ 's.

Finally, the relevant voting function for this case is just, 


$$
\mathrm{V}_{\mathrm{q}}(\mathrm{z}, \mathrm{k})=\beta \ln \left(\mathrm{p}_{\mathrm{kq}}(\mathrm{z})\right)-\mathrm{u}\left(\mu_{\mathrm{q}}(\mathrm{z}) \mathrm{k}\right)
$$

The next proposition summarizes the behavior of the relevant variables under this equilibrium.

Proposition 4. Assume that the initial capital stock $\mathrm{k}_{0}$ is sufficiently small. Then,

(i) There is some $t_{0}^{*}$ such that for $0 \leq t \leq t_{0}^{*}$ :

(a) the equilibrium minimum quality $z_{t}$ is zero,

(b) the growth rate is constant and equal to $\gamma_{q}(0)$,

(c) pollution is increasing.

(ii) For $\mathrm{t}>\mathrm{t}_{0}^{*}$ :

(a) the equilibrium minimum quality is increasing and it grows without bound,

(b) the growth rate of total capital is decreasing over time,

(c) the level of pollution is increasing and it converges to $s_{q}^{*}$, where $s_{q}^{*}$ satisfies,

$$
u^{\prime}\left(s_{q}^{*}\right) s_{q}^{*}=\beta \alpha /(1+v / \theta)
$$

Remark: If $z_{M}>0$, then the chosen quality is strictly increasing for all values of $k$, and converges to $\mathrm{z}_{\mathrm{M}}$ as $\mathrm{k}$ converges to zero. Thus, in terms of time paths, it is increasing and bounded below by $\mathrm{z}_{\mathrm{M}}$.

Proof: The proof of this result closely follows the arguments in Propositions 2 and 3 and is omitted (but is available upon request from the authors).

The behavior of pollution over time (as well as the minimum quality $z_{t}$ ) is shown in Figure 5. Under this system for collective decision making over environmental problems the economy shows an ever increasing level of pollution. This level grows faster during the initial period in which the minimum quality is given by $z_{M}$. After $t_{0}^{*}$ the increase in environmental standards decreases pollution per unit of output. However, the growth effect dominates resulting in an increasing level of pollution. Finally, this scheme succeeds in controlling pollution even in 
a growth environment: the asymptotic level of pollution is finite; moreover, it coincides with $s_{\tau}^{*}$ -the limiting level of pollution under the scheme in which taxes are used to regulate pollution. Thus, although the time paths of the two regimes are quite different, their asymptotic or long run behavior is the same. From a practical point of view this example points out the limitations of using long run or balanced growth arguments to interpret data. In this case, if one were interested in using the evidence to distinguish between the two possible regimes, ignoring the transition phase would be equivalent to giving up the possibility of identifying the correct regime.

\section{A Class of Optimal Allocations}

So far we have characterized the time path and the asymptotic behavior of pollution and income in two different equilibrium regimes. In both cases the old at time $t$ vote on either pollution taxes or minimum quality standards to be implemented at $t$, and the collective decision is made using majority voting. There are several concerns that arise: Are the voters too myopic since they ignore the impact of pollution on other individuals? In general, how do equilibrium levels of pollution compare to optimal levels of pollution?

It is well known that in overlapping generations models it is difficult to fully characterize the class of optimal allocations. However, in order to get an idea of the nature of the optimal pollution paths we consider a simple utilitarian social preference function. Let $U_{t}$ be the utility of generation $\mathrm{t}$, and assume that the planner maximizes

$$
W=\sum_{t=0}^{\infty} \beta_{p}^{t} U_{t}
$$

subject to the feasibility constraints. The discount factor $\beta_{\mathrm{P}}$ is assumed to be between 0 and 1 . The time path of the optimal solution is summarized in the next proposition.

Proposition 5. Assume that $\beta_{\mathrm{P}}(1-\delta+A)>1$ (to guarantee that the planner would be willing to grow), and that the initial capital stock $\mathrm{k}_{0}$ is sufficiently small. Then, the solution to the 
planner's problem is such that,

(i) There is some $t_{0}^{*}$ such that for $0 \leq t \leq t_{0}^{*}$ :

(a) the optimal level of quality $z_{t}$ is 0 ,

(b) the growth rate is constant and equal to $\gamma_{\mathrm{p}}(0)$,

(c) the level of pollution is increasing.

(ii) For $\mathrm{t}>\mathrm{t}_{0}^{*}$,

(a) the optimal quality level is increasing and converges to $\infty$ as $t$ goes to $\infty$,

(b) the growth rate of total capital is decreasing over time,

(c) the level of pollution is decreasing and it converges to $s_{p}^{*}$, where $s_{p}^{*}$ satisfies, $u^{\prime}\left(s_{p}^{*}\right) s_{p}^{*}=\left(\beta+\beta_{p}\right) \alpha /(1+v / \theta)$.

Proof: The planner's problem is

$$
\operatorname{Max} W=\sum_{t=0}^{\infty} \beta_{P}^{t}\left[\ln \left(c_{t}^{t}\right)+\beta \ln \left(c_{t}^{t-1}\right)-u\left(s_{t+1}\right)\right.
$$

subject to,

$$
\begin{aligned}
& \mathrm{c}_{\mathrm{t}}^{\mathrm{t}}+\mathrm{c}_{\mathrm{t}}^{\mathrm{t}-1} \leq \mathrm{B} \mathrm{\textrm {k } _ { \mathrm { ct } } ^ { \alpha }}, \\
& \mathrm{k}_{\mathrm{t}+1} \leq(1-\delta+\mathrm{A}) \mathrm{k}_{\mathrm{t}}+\left[(1-\delta)-(1-\delta+\mathrm{A}) \mathrm{m}\left(\mathrm{z}_{\mathrm{t}}\right)\right] \mathrm{k}_{\mathrm{ct}}, \\
& \phi\left(\mathrm{z}_{\mathrm{t}}\right) \mathrm{k}_{\mathrm{ct}} \leq \mathrm{s}_{\mathrm{t}}
\end{aligned}
$$

This statement of the planner's problem assumes that only one quality, $z_{t}$, is chosen at time $t$. A more general statement of the problem should allow for measures over $z$ 's as the relevant choice variable. Later in the proof we state the problem in this more general framework, and show that the optimum is such that only one quality is chosen at any given time.

The first order conditions for the planner's problem are, 
(P.5.1)

$$
\left(c_{t}^{t}\right)^{-1}-\lambda_{1 t} \leq 0
$$

$$
\left(c_{t}^{t-1}\right)^{-1}-\beta_{P} \lambda_{1 t} \leq 0
$$

$$
-u^{\prime}\left(s_{t}\right)+\beta_{p} \lambda_{3 t} \leq 0
$$

$$
\lambda_{1 \mathrm{t}} \alpha \mathrm{B} \mathrm{k}_{\mathrm{ct}}^{\alpha-1}+\lambda_{2 \mathrm{t}}\left[(1-\delta)-(1-\delta+\mathrm{A}) \mathrm{m}\left(\mathrm{z}_{\mathrm{t}}\right)\right]-\lambda_{3 \mathrm{t}} \phi\left(\mathrm{z}_{\mathrm{t}}\right) \leq 0
$$

$$
-\lambda_{2 t}(1-\delta+A) m^{\prime}\left(z_{t}\right)-\lambda_{3 t} \phi^{\prime}\left(z_{t}\right) \leq 0
$$

with the conditions holding at equality if the solution is interior. It is useful first to study the behavior of the solution in the interior case. Using the result that $\phi^{\prime}(z)=-v(1+z)^{-1} \phi(z)$, and $m^{\prime}(z)=\theta(1+z)^{-1} m(z),(P .5 .5)$ is,

$$
-\lambda_{2 t}+\beta_{\mathrm{P}}(1-\delta+\mathrm{A}) \lambda_{2 \mathrm{t}+1} \leq 0
$$

For future reference we point out that if $z=0$ then the relevant version of (P.5.7) is,

$$
\theta \lambda_{2 t}(1-\delta+A) m\left(z_{t}\right)=v \lambda_{3 t} \phi^{\prime}\left(z_{t}\right)
$$

Using (P.5.1), (P.5.2) and the feasibility constraint for the consumption sector, it follows that,

$$
1+\left(\beta / \beta_{\mathrm{p}}\right)=\lambda_{1 \mathrm{t}} \mathbf{B} \mathbf{k}_{\mathrm{ct}}^{\alpha}
$$

Substituting in (P.5.8) in (P.5.4) and imposing (P.5.7) we get,

$$
1+\left(\beta / \beta_{\mathrm{p}}\right)=\lambda_{2 \mathrm{t}} \mathrm{k}_{\mathrm{ct}}\left[(1+\theta / v)(1-\delta+\mathrm{A}) \mathrm{m}\left(\mathrm{z}_{\mathrm{t}}\right)-(1-\delta)\right]
$$


Next, use this expression (and (P.5.7)) in (P.5.3) to get,

$$
u^{\prime}\left(s_{t}\right) s_{t}=\alpha\left(\beta+\beta_{p}\right)(\theta / v)(1-\delta+A) m\left(z_{t}\right) /\left[(1+\theta / v)(1-\delta+A) m\left(z_{t}\right)-(1-\delta)\right]
$$

Equation (P.5.10) completely summarizes the behavior of pollution in any interior solution. Direct calculation shows that the right hand side of (P.5.10) is decreasing in $\mathrm{z}_{\mathrm{r}}$. Thus, if $\mathrm{z}_{\mathrm{t}}$ is increasing in equilibrium (we will show this to be the case), $\mathrm{s}_{\mathrm{t}}$ is decreasing. Taking into account that $s_{t}=\phi\left(z_{t}\right) k_{c}$, it follows from (P.5.10) that if $\lim _{t \rightarrow \infty} k_{a}=\infty$ (we will show this to be the case as well) then $\lim _{\mathrm{z} \rightarrow \infty} \mathrm{z}_{\mathrm{l}}=\infty$. To show that $\mathrm{k}_{\mathrm{a}} \rightarrow \infty$, suppose to the contrary that it remains in a bounded set. In this case (P.5.10) also implies that $z_{\mathrm{t}}$ remains in some bounded set. Using (P.5.5) it follows that $\lambda_{2 t}$ is bounded. However, since $\beta_{\mathrm{P}}(1-\delta+A)>1,(P .5 .6)$ implies that $\lambda_{2 t} \rightarrow \infty$, which gives rise to a contradiction. Thus, $\mathrm{k}_{\mathrm{ct}} \rightarrow \infty$ and, consequently $\mathrm{z}_{\mathrm{t}} \rightarrow \infty$.

Finally, the limit of the right hand side of (P.5.10) as $\mathrm{z} \rightarrow \infty$ is $\left(\beta+\beta_{\mathrm{P}}\right) \alpha /(1+v / \theta)$. Thus, it follows that $s_{t}$ is decreasing (if $z_{p}>0$ ) and converges to $s_{p}^{*}$, where

$$
u^{\prime}\left(s_{p}^{*}\right) s_{p}^{*}=\left(\beta+\beta_{\mathrm{p}}\right) \alpha /(1+v / \theta)
$$

We next show that for $\mathrm{k}$ small, the optimal solution is a corner solution with $\mathrm{z}=0$. For this to be the case it is sufficient that (P.5.7') hold. The appropriate version of (P.5.10) is,

$$
\mathrm{u}^{\prime}\left(\phi(0) \mathrm{k}_{\mathrm{c}}\right) \phi(0) \mathrm{k}_{\mathrm{ct}}<\alpha\left(\beta+\beta_{\mathrm{p}}\right)(\theta / v)(1-\delta+\mathrm{A}) /[(1+\theta / v)(1-\delta+\mathrm{A})-(1-\delta)]
$$

which clearly must hold for small $\mathrm{k}$ since $\mathrm{k}_{\mathrm{c}}$ is bounded above by $\mathrm{k}$, and the left hand side is converging to 0 as $k_{c} \rightarrow 0$.

To complete the proof we show that $\mathrm{z}_{\mathrm{t}}$ is indeed increasing (and in passing we also show that only one $z$ is chosen at time $t$ ). To do this, it is convenient to write the planner's problem as a dynamic problem with the choice variable being a measure, $\mu$, over the space of possible qualities (which we denote $Z$ ), with the interpretation that $\mu(\{z\})$ is the amount of capital of type 
$\mathrm{z}$ that the planner allocates to the consumption sector. With this relabeling, the appropriate version of Bellman's equation for the planner's problem is (see Stokey and Lucas (1989) for details on this),

$$
V(k)=\operatorname{Max}_{\mu, \mathbf{x}, \mathbf{k}^{\prime}}\left\{f(\mu)+\beta V\left(k^{\prime}\right)\right\}
$$

subject to,

$$
\begin{aligned}
& k \geq \int m(z) \mu(d z)+x, \\
& k^{\prime} \leq(1-\delta)\left[\int \mu(d z)+x\right]+A x .
\end{aligned}
$$

Here, $f(\mu)$ is the indirect utility function given by,

$$
f(\mu)=\max \left\{\ln \left(c_{y}\right)+\beta \ln \left(c_{o}\right)-u(s)\right\}
$$

subject to,

$$
\begin{aligned}
& c_{y}+c_{o} \leq B\left[\int \mu(d z)\right]^{\alpha} \\
& s \leq \int \phi(z) \mu(d z),
\end{aligned}
$$

and where the maximization is over $c_{y}, c_{o}$ and $s$. Straightforward calculations show that the function $\mathrm{f}$ is a strictly concave function of $\mu$. Next a direct application of the arguments in Stokey and Lucas (1989) (Theorem 4.8) shows that the value function for the planner's problem, $\mathrm{V}(\mathrm{k})$, is strictly concave. This follows because the objective function is strictly concave and the constraint set is convex (in fact linear) in the choice variables. The arguments used by Benveniste and Scheinkman (1979) apply to our problem and establish that $V$ is differentiable when the solution is interior (see the discussion in Stokey and Lucas (1989) Theorems 4.10 and 4.11).

Even though we stated the planner's problem in a general way by allowing measures to 
be the choice variable, it is easy to see that the optimal measure would be a Dirac measure that puts mass $k_{c t}$ on the set $\left\{z_{t}\right\}$, where $k_{c t}$ and $z_{t}$ are the variables characterized in the planner's problem at the beginning of the proof. To prove this note that both $\mathrm{m}(\mathrm{z})$ and $\phi(\mathrm{z})$ are convex ( $\phi(\mathrm{z})$ is strictly convex given our assumptions about relevant parameter values), and a direct application of Jensen's inequality establishes that a point mass measure on some $z_{t}$ dominates any measure that puts positive mass on more than one point. Thus, in the planner's problem stated at the beginning of the proof, the assumption that there is a unique $\mathrm{z}_{\mathrm{t}}$ is without loss of generality.

Finally, to establish that the sequence $z_{t}$ is increasing when it is interior (we already showed that there is a region in which it is zero), rewrite the palnner's problem as,

$$
\max \left\{C_{0}+\alpha(1+\beta) \ln \left(k_{c}\right)-u\left(\phi(z) k_{c}\right)+\beta V\left[(1-\delta) k_{c}-(1-\delta+A)\left(k-m(z) k_{c}\right]\right\}\right.
$$

where $\mathrm{C}_{0}$ is a constant. This formulation already incorporates the result that the choice of $\mathrm{z}$ is unique. Let the function inside set brackets be denoted $M\left(k_{c}, z ; k\right)$. It follows from the concavity of $V$ that the function is supermodular (see Topkis (1979) and Milgrom and Shannon (1994)) and hence that higher values of $\mathrm{k}$ result in higher values of $\mathrm{z}$. However, since the growth rate is positive, the sequence $k_{t}$ is increasing. Thus, the sequence $z_{t}$ increases as well.

There are some interesting differences between the planner's allocation and the allocations under either one of the two equilibrium regimes (choosing pollution taxes and regulating minimum quality levels). The basic details of the time path of the planner's choices of qualities and level of pollution are reflected in Figure 6. Note that the equilibrium path of pollution displays the U shape pattern that Grossman and Krueger (1994) emphasize.

The planner's allocation is such that pollution converges to a long run level $\mathrm{s}_{\mathrm{p}}^{*}$. This level is strictly greater than the long run level in either one of the equilibrium solutions (they are the 
same). Thus, it follows that the planner's allocation entails strictly more pollution than the equilibrium allocation when minimum quality levels are chosen in the sense that one curve lies strictly above the other. It is more difficult to determine how the planner's solution compares with the equilibrium solution when taxes are the instrument. All that can be said is that for very high levels of capital (and, hence, income) the planner's choice of pollution is higher than the equilibrium. Thus, at least for high levels of income the models predict excessive conservation associated with the equilibrium solutions. The reason why the planner chooses more pollution in the limit is easy to ascertain: it cares about future generations more than voters do. In this setting in which there are no intergenerational spillovers of pollution, voters fail to take into account the impact of the more expensive capital on the welfare of future generations. Note that as the discount factor in the planner's problem is driven to zero all three solutions coincide in the long run.

Why is it that the market solution for a given sequence of minimum standards $\left\{z_{t}\right\}$ differs from the planner's allocation? More precisely, suppose that majority voting would have resulted in a sequence $\left\{z_{t}\right\}$ identical to the planner's choice of optimal $\left\{z_{t}\right\}$; even in this case the time path described in Figure 5 still describes the evolution of pollution: fast increases for low levels of income, and smaller but positive increases at higher levels. This is quite different from the inverted $U$ shape in Figure 6. The resolution of this puzzle lies in the fact that the solutions to planner's problems like the one we used in this section are in general difficult to decentralize as laissez faire equilibria in overlapping generations models. Typically, it is necessary to implement a sequence of transfers so that the post-transfer equilibrium will implement the planner's allocation. An extreme example of this is the class of one sector endogenous growth models. In those models the planner's problem of the type considered in this section (which of course coincides with the equilibrium in an economy with infinitely lived agents) results in positive growth (under some assumptions on parameters), while it is well known (see Boldrin (1992) and Jones and Manuelli (1992)) that there is no equilibrium growth in an overlapping generations setting. Thus, the only way in which the planner's solution can be implemented as a competitive equilibrium is with the use of extensive intergenerational transfers. To some extent the same issues cloud the comparison of the time paths of pollution chosen by the planner and those 
chosen by voters in this setting. However, it is possible to show that even if the planner has a time varying discount factor $\beta_{\mathrm{pt}}$ (this is in general necessary to replicate the market solution), our asymptotic results about the lower than optimal pollution produced by the market obtain whenever the planner asymptotically gives some value to the future. More precisely, if $\lim _{t \rightarrow \infty}$ $\beta_{\mathrm{pl}} / \beta_{\mathrm{pt+1}}>0$, it is still the case that the planner asymptotically choose more pollution than either of the equilibrium regimes.

\section{Extensions}

There are some extensions of the model that are straightforward and do not alter the qualitative properties of the results.

a) Global External Effects. The model can be easily extended to one in which pollution is global. There, for a small country, the level of pollution is independent of local activities. It is straightforward to show that in this case, no local pollution controls are enacted.

b) Pollution as a stock variable. In section 2 we assumed that pollution is a flow: the amount of smoke generated today affects only today's utility. If instead, pollution is treated as a capital stock in which the amount produced at $t$ increases that stock, the analysis in section 2 remains basically unchanged. In this case, however, the welfare comparisons are more difficult.

c) Heterogeneity . The assumption of identical individuals is convenient but not essential. First if different individuals have different amounts of initial wealth --say due to differences in their labor endowment or government transfers-- our results in sections 2-4 go through as they are. The key observation is that the relevant voting function even in this case depends on just the amount of pollution and the unit price of capital. If individuals have different disutility from pollution (different $\mathrm{u}$ functions) then additional assumptions to guarantee that the median voter theorem holds are necessary. However, given those assumptions the analysis proceeds as in sections 2 and 4. 
d) The uses of tax revenue. In the analysis of section 2 we assumed that the proceeds from the environmental tax are thrown away (or, equivalently used to finance a public good whose utility is separable with respect to the other variables). There are at least three simple alternatives: use the proceeds to "clean" the environment, make a transfer to the young or to the old. In the first case --and depending on how the cleaning up technology is specified-- the qualitative results remain the same. If the tax revenue is used to finance a transfer to the young, it is possible to obtain the puzzling result that higher taxes increase the growth rate. This is a standard result in overlapping generations models (see Boldrin (1992) and Jones and Manuelli (1992)). Finally, if the proceeds from taxing low quality capital are used to finance a transfer to the old, the problem becomes substantially more complicated: in this case the saving function will depend on the interest rate and hence the voting decision must be modeled as a complicated game with an uncountable number of agents. Even though this is an interesting (and realistic) situation it seems to add a level of complication that is hard to justify.

e) Alternative technologies. In this paper we emphasized the possibility that different capital stocks that are useful in producing consumption also produce pollution. An alternative would be to consider "clean" and "dirty" capital goods that can be used in both sectors. There are problems with these alternative specifications. If there are multiple capital goods in the production sector, it is possible that the voting problem is not well defined. The reason for this is simple: by increasing the price of capital (say through higher taxes) the old increase their consumption while at the same time reducing pollution. In this setting the optimal private tax is infinite. Alternatively, one can consider multiple capital goods in the consumption sector. The problem in this case is that tax increases devote more resources to the capital sector and this increases the growth rate. Therefore, such a model would have the implication that higher pollution taxes are growth enhancing. It seemed that this is at odds with the evidence and, hence, we decided against this model.

\section{Concluding Comments}

There are several conclusions that emerge from this analysis. It is possible to separate them into 
two categories: those specific to the issue of growth and the environment and those that are more general and point to the potential of endogenous policy models to explain growth facts.

i) One of the questions we phrased at the beginning of this paper concerned the extent to which individuals acting in their own self interest through collective choice mechanisms have the incentive to control external effects. Even though pollution would converge to infinity in the absence of collective choice, voting mechanisms provide sufficient incentives to bound pollution at the cost of lower growth. The fact that this holds for both of the mechanisms (i.e., voting on taxes and voting on qualities) that we analyze suggests that this result is robust to the details of the collective choice mechanism.

(ii) The models that we analyze display dynamic paths that vary in subtle ways with the details of the institutional structure. For example, even though the limiting level of pollution is the same under both voting on taxes and voting over quality regulation, the time paths followed by both pollution and income are quite different. This finding illustrates a property that is likely to be shared by many models of endogenous policy choice. This is that even though the long run behavior is invariant to the choice of institutions, the qualitative nature of the path that is followed could be quite different.

iii) Our analysis suggests that even in cases in which policy decisions about pollution control are made without consideration of future generations, it does not follow that the equilibrium level of pollution is excessive. In particular, the analysis in sections 2 and 3 suggest exactly the opposite: there are equilibrium allocations that --at least asymptotically-- result in too little pollution. This feature of the equilibrium is likely dependent on the fact that, in this formulation, the choices of the voting generation with respect to pollution do not affect future generations. In particular, this will no longer hold if either the young are directly affected by pollution (and they are still not allowed to vote) or if pollution has a stock component to it.

iv) There is a more general point about the relationship between public policy and growth that this paper makes. It shows that by endogeneizing policy choices it is possible to capture some of 
the stylized facts that seem to characterize cross country growth data. Of course, for this to be the case it is necessary that the equilibrium be of the non-balanced growth variety: it is necessary for policies to change with income levels, which is impossible on a balanced growth path. This paper suggests that models of endogenous policy choices in non-balanced growth environments are tractable and potentially useful to interpret cross country growth data. More specifically, the model implies:

a) In the equilibrium in which individuals vote on taxes, growth rates are constant at very low levels of income. This is followed by a period of increasing growth rates and, finally, by a long run trend for growth rates to coincide. It is quite possible that a convergence regression would yield a positive, negative or zero coefficient on initial income depending on the mix of countries in the three regions. Moreover, our results suggest a possible model consistent with the finding of the existence of "convergence clubs." Specifically, our model implies that there are two convergence clubs: the low income countries and the high income countries. In the case of the latter (we interpret high income as those countries that have entered the last phase) the model implies that in a regression of growth on initial income the coefficient should be negative. Note however, that there are no multiple equilibria. In other words, in this model all countries eventually join the "high income club."

b) The observation that the cross sectional relationship between growth rates and income is an inverted U (see Easterly (1994) and Cho (1994)) is also consistent with this model. However, the insight that one gets is quite different from the argument developed by Easterly. This argument relies on minimum consumption levels and decreasing marginal product of capital to induce relatively low savings at both ends of the income spectrum. In our case, it is the endogenous choice of policies that respond to the interest of voters that produces the same inverted $U$ shape pattern in equilibrium.

c)The model also implies that trying to separate the effects of policies from those of initial conditions is fruitless: the two variables are perfectly correlated. In particular -- 
using the voting-over-taxes equilibrium as the basic model-- it follows that higher income levels "cause" higher taxes which, in turn, decrease future growth. This endogeneity of policies far from being a theoretical curiosity is probably quite prevalent. This model simply illustrates the danger of giving structural interpretations to reduced forms. 


\section{References}

Alessina, A. and D. Rodrik. (1994). "Distributive Politics and Economic Growth," Quarterly Journal of Economics, Vol CIX, Issue 2, pp 465-90.

Baumol, W.J. and, Oates, W.E. (1979). Economics, Environmental Policy, and the Quality of Life. Englewood Cliffs: Prentice Hall.

Baumol, W.J. and Oates, W.E. (1988). The Theory of Environmental Policy. 2nd edition. Cambridge: Cambridge University Press.

Boldrin, M. (1992). "Dynamic Externalities, Multiple Equilibria and Growth," Journal of Economic Theory, Vol. 58, No. 2, 198-218.

Cho, D. (1995). “An Alternative Interpretation of Conditional Convergence Results,” Working Paper, Department of Economics, Texas A\&M University.

Easterly, W. (1994). “Economic Stagnation, Fixed Factors, and Policy Thresholds,” Journal of Monetary Economics, Vol. 33, No. 3, pp 525-557.

Fisher, E.O. and van Marrewijk, C. (1994). "Pollution and Economic Growth in a Model of Overlapping Generations," Ohio State University, Working Paper.

Glomm, G. and B. Ravikumar. (1992). "Public Versus Private Investment in Human Capital: Endogenous Growth and Income Inequality," Journal of Political Economy, 100 (4), pp 818834.

Glomm, G. and B. Ravikumar. (1994). "Endogenous Public Policy and Multiple Equilibria," Econometrics and Economic Theory Paper No. 9301, Michigan State University. 
Grossman, G. and Krueger, A.B. (1995). "Economic Growth and the Environment," Quarterly Journal of Economics, Vol. CX, Issue 2, pp 353-377.

Grossman, G. and Krueger, A.B. (1991). "Environmental Impacts of a North American Free Trade Agreement." Paper prepared for the Conference on United States-Mexico Free Trade Agreement.

Jones, L.J. and Manuelli, R. E. (1992). "Finite Lifetimes and Growth," Journal of Economic Theory, Vol. 58, No. 2, 1, pp 171-97.

Krusell, P., Quadrini, V. and J.V. Rios-Rull (1995). "Politico-Economic Equilibrium and Economic Growth,” Journal of Economic Dynamics and Control, (forthcoming)

Levinson, A. (1994). "Environmental Regulations and Manufacturers' Location Choices: Systematic Evidence From the Census of Manufactures," University of Wisconsin-Madison, Working Paper.

Low, P. (ed.) (1992). International Trade and the Environment. World Bank Discussion Paper \#159. The World Bank.

Low, P. and Yeats, A. (1992). "Do 'Dirty' Industries Migrate," in Low, P. (ed) International Trade and the Environment.

Lucas, R.E.B., Wheeler, D. and Hettige, H. (1992). "Economic Development, Environmental Regulation and the International Migration of Toxic Industrial Pollution: 1960-88," in Low, P. (ed.) International Trade and the Environment.

Malthus, T.R. (1798). An Essay on Population. London: McMillan and Co Ltd. (Reprinted 1926.) 
Meadows, D.H., Meadows, D.L. and Randers, J. (1972). Limits to Growth. New York:

Universe Books, 1972.

Mohtadi, H. (1994). "Environment, Development and Growth: Explaining the Evidence and Designing Optimal Policies," University of Wisconsin-Milwakee, Working Paper.

Milgrom, P. and C. Shannon, (1994). "Monotone Comparative Statics," Econometrica, 62 (1), pp. 157-180.

Persson, T. and G. Tabellini, (1994). "Is Inequality Harmful for Growth," American Economic Review, Vol 84 (3), pp 600-21.

Romer, P. (1986). "Increasing Returns and Long Run Growth," Journal of Political Economy, $94,1002-1037$.

Stokey, N.L. (1988). "Learning by Doing and the Introduction of New Goods," Journal of Political Economy, 96, 701-717.

Stokey, N.L. (1991). "Human Capital, Product Quality and Growth," Quarterly Journal of Economics, CVI, Issue 2, 587-616.

Topkis, D. (1978). "Minimizing a Submodular Function on a Lattice," Operations Research, 26, pp. 305-321.

O.E.C.D. (1991). The State of the Environment. Paris: O.E.C.D.

The World Bank (1992). World Development Report 1992: Development and the Environment. Oxford University Press. 


\section{Appendix}

Given the new variable $y=\left(\tau / \tau_{L}\right)^{\theta / v}$, the equilibrium level of $\mathrm{z}$ as function of $\mathrm{y}$ is given by,

$$
z(y)= \begin{cases}0 & \text { for } y \leq 1 \\ y^{1 / \theta}-1 & \text { for } y \geq 1\end{cases}
$$

Given this function $z(y)$, the cost of capital in the consumption sector given a tax rate implied by $y$ is,

$$
m(y)= \begin{cases}1 & \text { for } y \leq 1 \\ y & \text { for } y \geq 1\end{cases}
$$

while pollution per unit of capital in the consumption sector (again as a function of the tax rate) is,

$$
\phi(y)= \begin{cases}D & \text { for } y \leq 1 \\ D y^{-v / \theta} & \text { for } y \geq 1\end{cases}
$$

With these two functions it is immediate to derive an expression for the after tax cost of capital in the consumption sector. It is given by,

$$
(1+\tau \phi) \mathrm{m}=\left\{\begin{array}{cc}
1+\mathrm{y}^{v / \theta} \frac{\theta}{v-\theta} & \text { for } \mathrm{y} \leq 1 \\
y\left(1+\frac{\theta}{v-\theta}\right) & \text { for } \mathrm{y} \geq 1
\end{array}\right. \text {. }
$$


Using equations (2.10) and (2.11) evaluated at the equilibrium levels of all the variables as functions of the tax rate, $y$, it is possible to calculate the fraction of the total capital stock allocated to the consumption sector. This fraction is,

$$
k_{c}(y) / k= \begin{cases}\frac{\alpha(1+\beta)(1-\delta+A)}{(1-\alpha) \beta A\left[\left(1+\frac{\theta}{v-\theta} y^{v / \theta}\right)+\frac{\alpha}{1-\alpha} \frac{1+\beta}{\beta}\right]} & \text { for } y \leq 1 \\ \frac{\alpha(1+\beta)(1-\delta+A)}{(1-\alpha) \beta A\left[\left(1+\frac{\theta}{v-\theta}\right) y+\frac{\alpha}{1-\alpha} \frac{1+\beta}{\beta A}((1-\delta+A) y-(1-\delta))\right]} & \text { for } y \geq 1\end{cases}
$$

Finally, given the ratio $\mathrm{k}_{c} / \mathrm{k}$ and $\phi$, it follows that pollution per unit of total capital and the unit price of capital as functions of the tax rate $y$ are given by equations (2.16) and (2.17) in the text. 
Figures
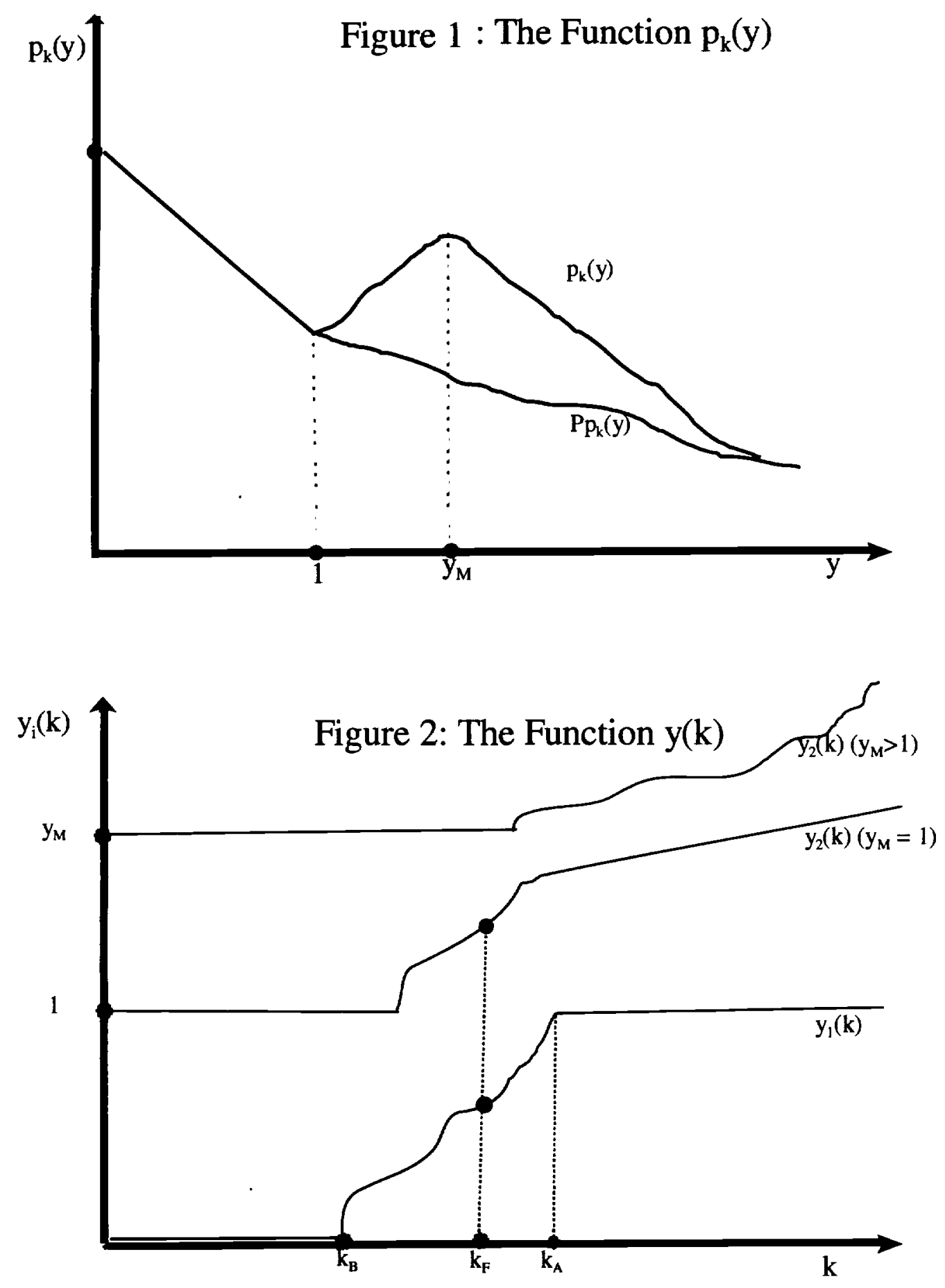


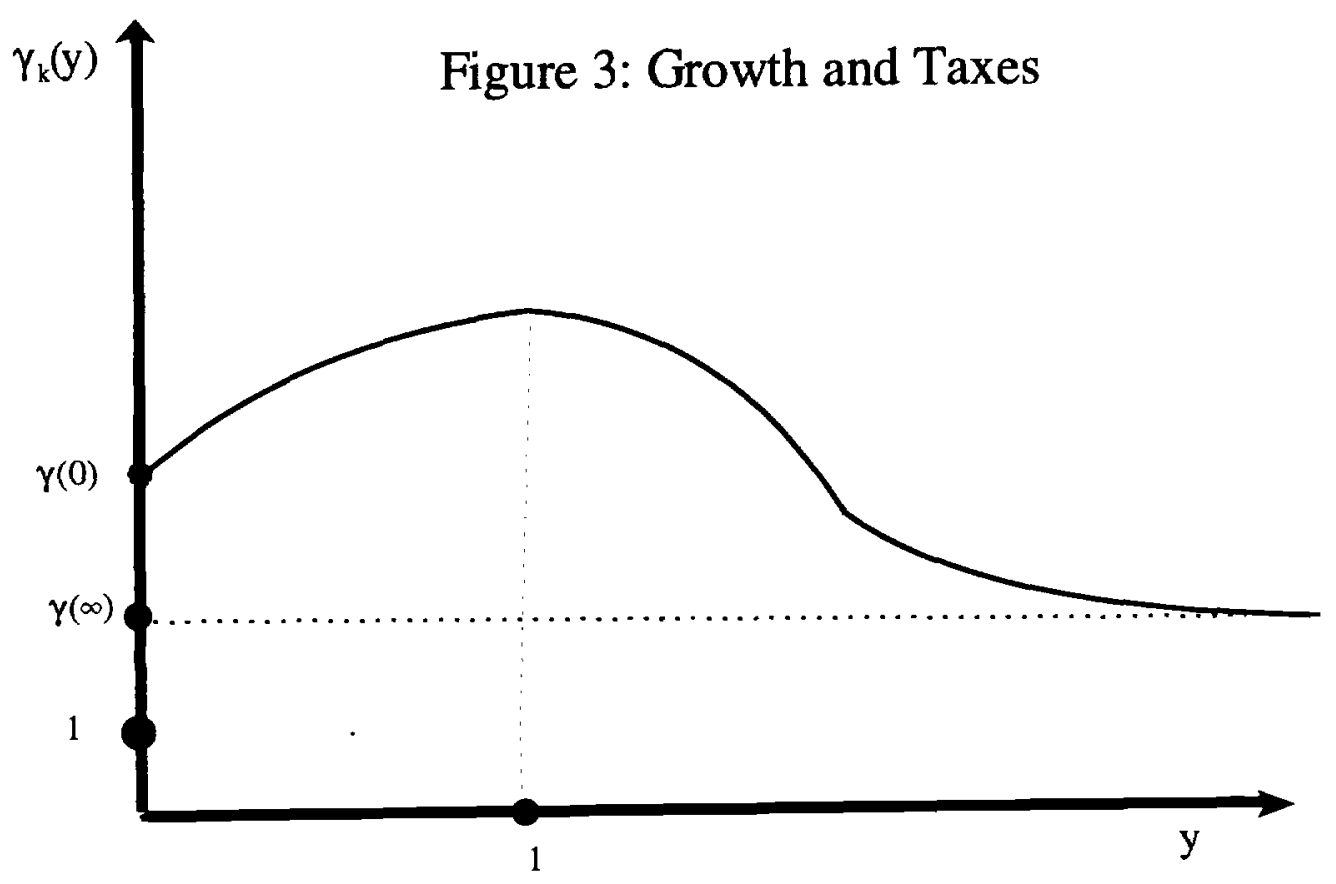


Figure 5: Time Path of Pollution and $\mathrm{z}$ - Voting Model
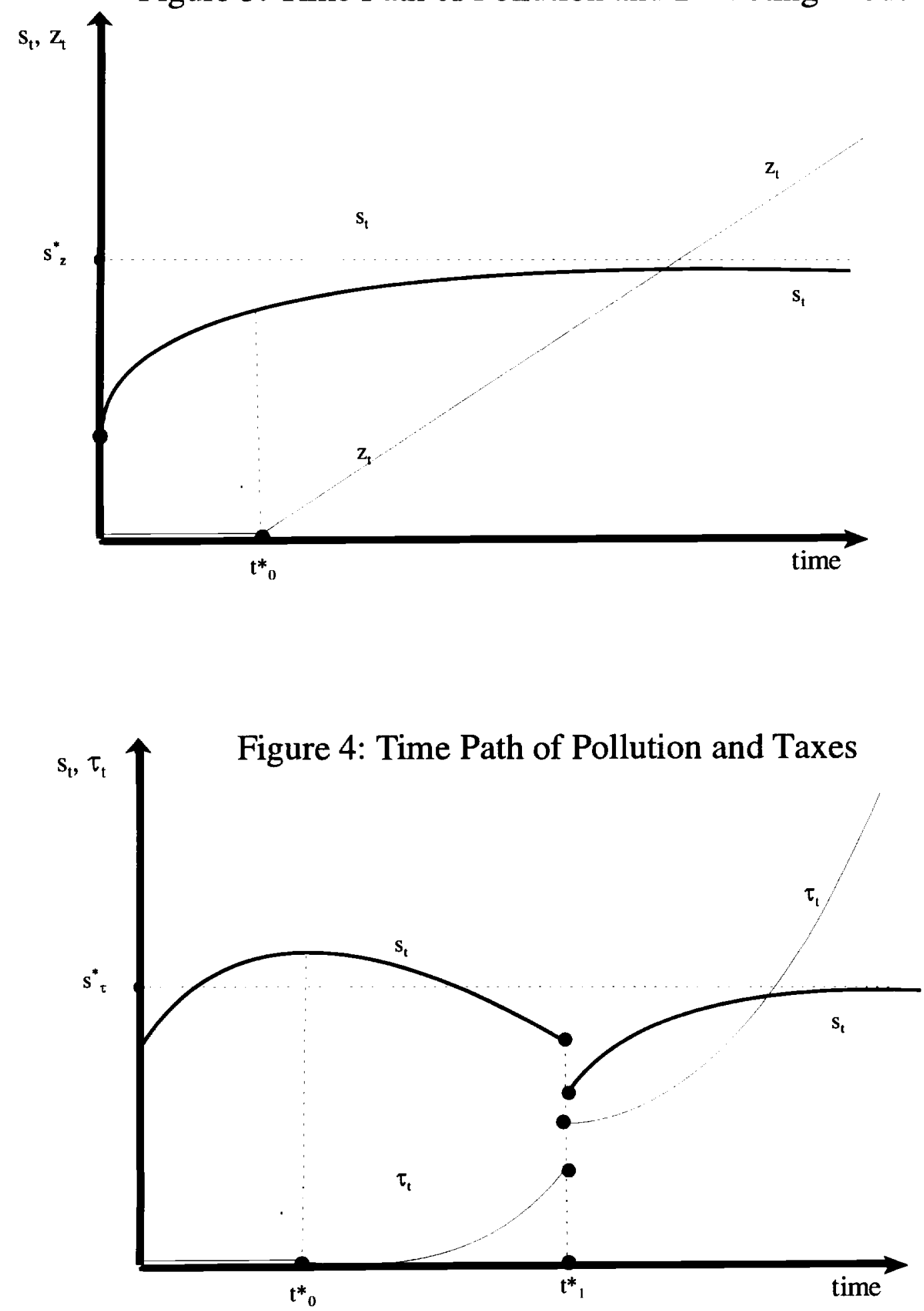
Figure 6: Time Path of Pollution and z - Planner Problem

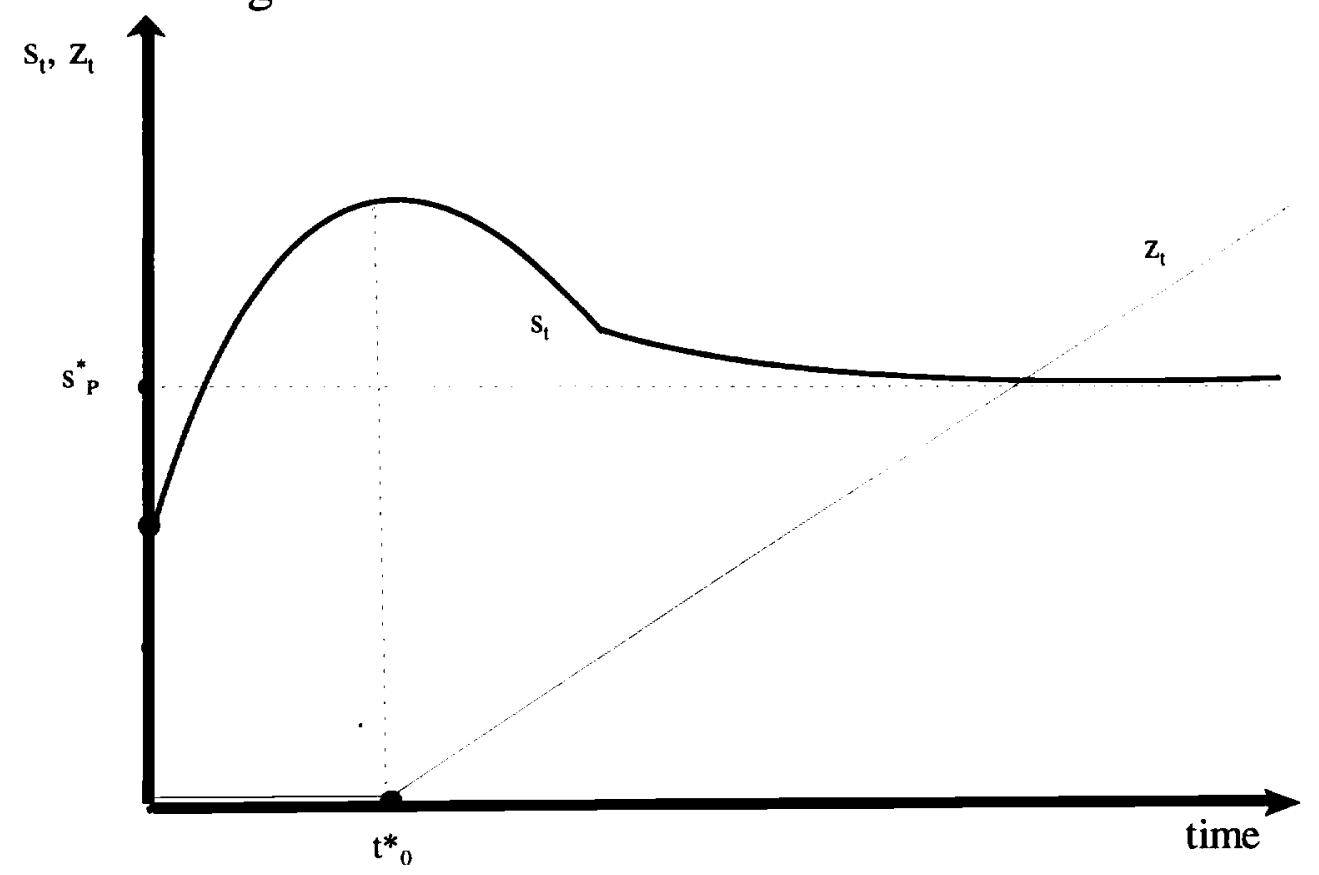

Appe 


\section{Apendix B: Sketch of the proof of Proposition 4}

We first characterize how the optimal $\mathrm{z}$ varies with $\mathrm{k}$. With this done, the assumption on parameters that imply that $\mathrm{k}$ is strictly increasing over time result in the behavior of time paths as stated in the proposition. Using (4.1) and (4.2) as well as the indirect utility function $V_{q}$, it follows that,

$$
\begin{array}{r}
\partial \mathrm{V}_{\mathrm{q}} / \partial \mathrm{z}=\beta \mathrm{m}^{\prime}(\mathrm{z}) / \mathrm{m}(\mathrm{z})\left\{\left[(1-\alpha) \mathrm{m}(\mathrm{z}) \mathrm{a}_{0} /\left(\mathrm{a}_{0} \mathrm{~m}(\mathrm{z})-\mathrm{a}_{1}\right)\right]-1\right\}+ \\
\mathrm{u}^{\prime}\left(\mu_{\mathrm{q}}(\mathrm{z}) \mathrm{k}\right) \mu_{\mathrm{q}}(\mathrm{z}) \mathrm{k}\left[\mathrm{a}_{0} \mathrm{~m}^{\prime}(\mathrm{z})+\mathrm{v}(1+\mathrm{z})^{-1}\right] /\left[\mathrm{a}_{0} \mathrm{~m}(\mathrm{z})-1\right]
\end{array}
$$

Given our assumptions about $\mathrm{u}$, the second term converges to zero as $\mathrm{k}$ goes to zero. Thus, to establish that for small $\mathrm{k}$ the equilibrium $\mathrm{z}$ will be zero, it suffices to show that

$$
\beta m^{\prime}(z) / m(z)\left\{\left[(1-\alpha) m(z) a_{0} /\left(a_{0} m(z)-a_{1}\right)\right]-1\right\}>0 .
$$

Simple algebraic manipulations show that this inequality holds if and only if,

$$
m(z)>a_{1} / \alpha a_{0} .
$$

Note that the assumption $\mathrm{z}_{\mathrm{M}}=0$ requires $1>\mathrm{a}_{1} / \alpha \mathrm{a}_{0}$, which completes the argument as $\mathrm{m}(\mathrm{z}) \geq 1$.

Next we characterize the equilibrium $\mathrm{z}$ as a function of $\mathrm{k}$ when the solution is interior. Algebraic manipulation of the condition $\partial \mathrm{V}_{\mathrm{q}} / \partial \mathrm{z}=0$ show that it is equivalent to,

$$
\mathrm{S}(\mathrm{z})=\mathrm{G}(\mathrm{z}, \mathrm{k})
$$

where,

$$
\mathrm{G}(\mathrm{z}, \mathrm{k})=\mathrm{u}^{\prime}\left(\mu_{\mathrm{q}}(\mathrm{z}) \mathrm{k}\right) \mu_{\mathrm{q}}(\mathrm{z}) \mathrm{k}
$$


and,

$$
S(z)=\left[\left(a_{0} m(z)-a_{1}\right)-(1-\alpha)\right] /\left[(v / \theta)\left(a_{0} m(z)-a_{1}\right)+a_{0} m(z)\right]
$$

It follows that $G(z, k)$ is decreasing in $z$ and increasing in $k$, while $S(z)$ is increasing in $z$. Figure $B$ shows possible $S$ and $G$ functions. Note that the optimal $\mathrm{z}$ is unique, and that it increases as $\mathrm{k}$ increases. Moreover, as proved above, for small $\mathrm{k} G(0, \mathrm{k})<\mathrm{S}(0)$, and the equilibrium $\mathrm{z}$ is zero. 


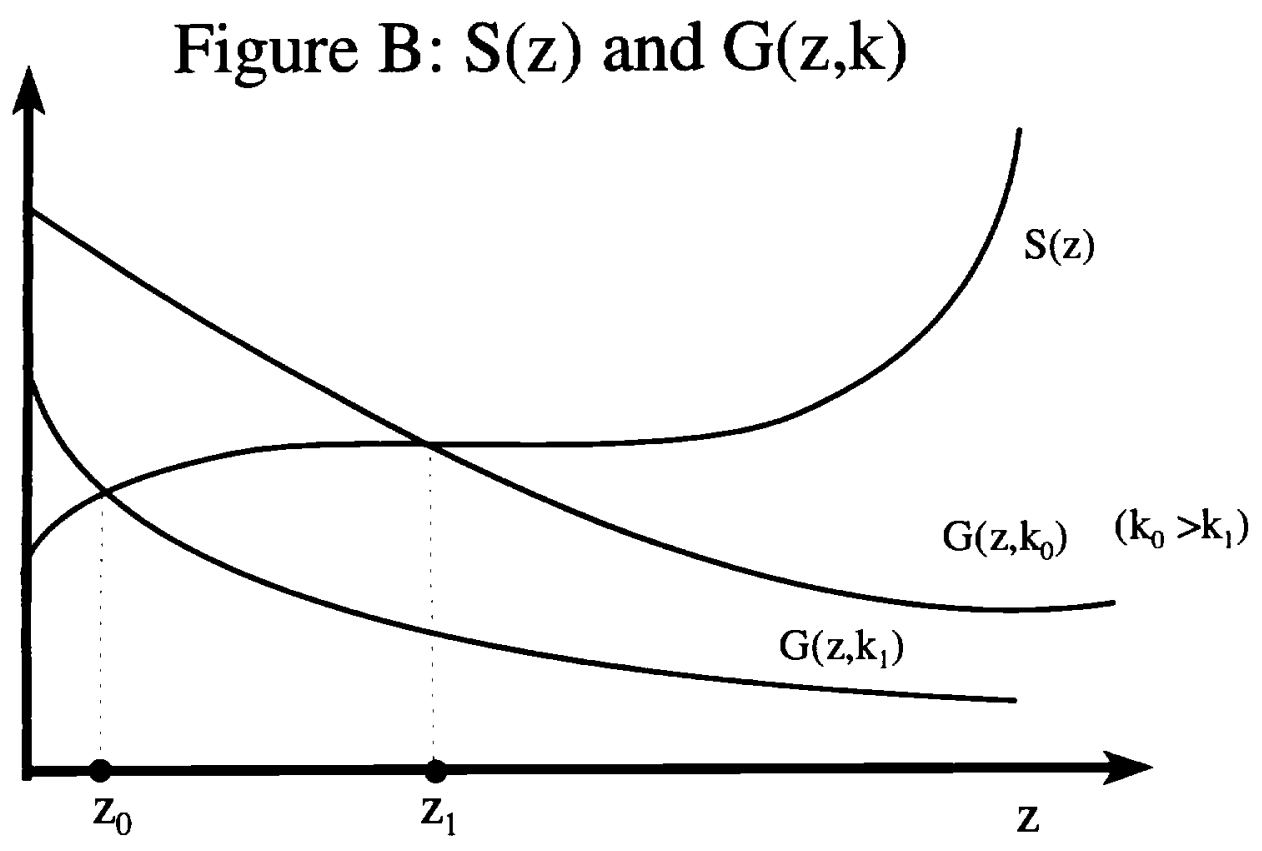

